\title{
EL VALOR DEL CONCEPTO VIDA EN GARCÍA BACCA, Y SU RELACIÓN INICIAL CON LA FILOSOFÍA DE ORTEGA Y GASSET
}

\author{
THE V ALUE OF GARCÍA BACCA'S LIFE CONCEPT AND ITS INITLAL \\ RELATIONSHIP WITH ORTEGA Y GASSET'S PHILOSOPHY
}

Xavier Gimeno Monfort

Recibido: 01/04/2015

Aceptado: 05/06/2015

\section{RESUMEN}

El presente articulo pretende exponer del modo más claro y sintético, un tema poco trabajado y aún menos conocido por gran parte de la academia filosófica española, a saber, el sentido histórico y filosófico que determina parte de la propia génesis del proyecto metafísico del filósofo del exilio español Juan David García Bacca. Para ello, hemos centrado nuestros esfuerzos en tratar de exponer y aclarar el peso determinante que la filosofía del José Ortega y Gasset ejerció sobre el filósofo español, con el fin de poder determinar hasta qué punto y, de qué modo, fue clave en la gestación y nacimiento del proyecto metafísico garcibaccquiano. Hemos tratado de definir y medir dicha influencia a través del análisis de conceptos de origen orteguiano tales como la vida y los tipos de razón con el fin de aclarar el peso real de dicha influencia sobre el filósofo español.

Palabras Clave: Ortega y Gasset, García Bacca, vida, raciovitalismo, metafísica

\section{ABSTRACT}

This article aims to present in the clearest and most concise possible fashion a theme which has attracted little attention and therefore is almost unknown in the Spanish 
philosophical Academy, namely the historical and philosophical sense that determines part of the genesis of the Spanish philosopher Juan David Garcia Bacca's metaphysical philosopher project. In order to achieve our goal, we will try to explain and clarify the primary role that the philosophy of José Ortega y Gasset exerted on Bacca's philosophy, with the objective of determining to what extent and in what way it was fundamental in the genesis of Bacca's project. We sought to define and measure this influence through the analysis of concepts characteristic of Ortega such as life and that of types of reason in order to clarify the actual weight of this influence on Bacca.

KEYWORDS: Ortega y Gasset, Garcia Bacca, life, ratiovitalism, metaphysics

\section{INTRODUCCIÓN.}

En el presente artículo pretendemos abordar el peso e influencia ejercido por el filósofo español José Ortega y Gasset sobre la gestación y nacimiento de la propuesta metafísica de Juan David García Bacca. Gestación y nacimiento que se desarrolla durante un periodo de tiempo muy concreto dentro de la obra garcibacquiana, a saber, durante los primeros años de la década de los 40 del pasado siglo. Años en los que García Bacca está gestando su propio propuesta metafísica sobre algunos principios metafísicos orteguianos. Para tratar de analizar hasta qué punto Ortega ejerció verdadera influencia sobre la obra de García Bacca nos referiremos, esencialmente, a dos de las obras de sus obras donde, de modo más claro y riguroso, García Bacca aborda el figura y pensamiento de Ortega. Nos referiremos en su momento, a las obras de García Bacca Nueve grandes filósofos e Introducción al filosofar respectivamente.

A pesar de centrar el presente trabajo en un periodo tan concreto dentro de la obra de García Bacca, -primeros años de la década de los 40 del pasado siglo-, cabe señalar que la propuesta metafísica garcibacquiana se desarrolla a lo largo de poco más de 50 años (1939-1992). Durante esos 53 años, el filósofo español publica un sin fin de títulos que se reparten entre obras, artículos, seminarios, clases, reseñas y traducciones. Si bien la propuesta metafísica garcibacquiana es amplia y extremadamente variada en temas y sujeta múltiples variaciones y modificaciones, nosotros únicamente atenderemos en el presente 
artículo a la influencia ejercida por Ortega durante los primeros años del desarrollo de la propuesta metafísica garcibacquiana. ${ }^{1}$

Las principales referencias bibliográficas de García Bacca sobre la figura de Ortega son las siguientes:

- GARCíA BACCA, J. D. (1939): Introducción al filosofar, Universidad Nacional de Tucuman (Facultad de filosofía y letras).

- _ (1947): Nueve grandes filósofos contemporáneos y sus temas, Caracas: Imprenta Nacional, Ministerio de Educación de Venezuela. Nueva edición en 1990. Anthropos.

- _ (1956): "El estilo filosófico de J. Ortega y Gasset". Revista Nacional de cultura, $\mathrm{n}^{\circ} 114$.

(1955): "La filosofía de Ortega y Gasset", Revista Nacional de cultura.

En este caso, nosotros haremos uso de las que, a nuestro parecer, son las referencias bibliográficas más importantes y destacadas, a saber: Nueve grandes filósofos contemporáneos y sus temas e Introducción al Filosofar. Estas dos obras

\footnotetext{
${ }^{1}$ La obra filosófica de García Bacca -no sólo metafísica-, se extiende a lo largo de más de 60 años en los que publica casi un total de 500 títulos repartidos en obras, artículos, conferencias, traducciones y reseñas. Debido a la casi inconmensurable cantidad de títulos publicados, así como a la multitud de cambios de registro filosófico, la comunidad de expertos en la vida y obra de García Bacca ha dividido su producción filosófica generalmente en 4 periodos. Bajo nuestro criterio, hemos optado por la división en 4 etapas tal y como lo hacen algunas de las principales autoridades en la vida y obra del filósofo español, a saber: $1^{\circ}$ Etapa escolástica: (19281933). $2^{\circ}$ Etapa lógico-cientifica: (1933-1940). $3^{\circ}$ Etapa existencialista: $(1940-1960)$ y, finalmente $4^{\circ}$ Etapa Marxista: (1960-1992). En cualquier caso, la división en más o menos etapas es una cuestión que responde más a la necesidad o demanda por nuestra parte para otorgar cierta coherencia argumentativa dentro del discurso del filósofo español, que a una evidente separación en etapas dentro de la producción filosófica en García Bacca. Independientemente de la multitud de temas tratados por García Bacca, y a pesar de que el hilo conductor en su despliegue argumentativo siempre sea la propia dialéctica, a nuestro parecer, no existe un criterio definitivo para poder dividir la obra del filósofo español. Cualquier tesis que pretendiera asentar un criterio definido y seguro para dicha tarea sería, a nuestro juicio, de marcado carácter arbitrario. En el presente trabajo nos centramos en el periodo de transición entre la $2^{\circ}$ etapa de carácter lógico-científico, y la $3^{\circ}$ etapa de pensamiento garcibacquiano en el que parece gestarse el desarrollo de su periodo existencialista a propósito de la influencia de la filosofía de Ortega y Gasset. En cualquier caso, el desarrollo y exposición de cada etapa del pensamiento garcibacquiano excede en mucho el espacio del presente artículo. Para mayores referencias sobre el conjunto y reparto de la obra de García Bacca en etapas consultar (Cfr. IZUZQUiZA 1984; BEORLEGUi 1988; BEORLEGUi 2003).
} 
constituirán, grosso modo, las principales fuentes bibliográficas garcibacquinas sobre las que desarrollaremos nuestra exposición crítica respecto al impacto e influencia ejercida por Ortega en la vida y obra del filósofo español durante un periodo corto de tiempo pero clave para la comprensión de la propia evolución metafísica de García Bacca.

En especial, nosotros nos centraremos en el presente trabajo sobre el valor y sentido de la influencia del pensamiento de Ortega en el sistema metafísico garcibacquiano. Por otra parte, cabe destacar y señalar -cuando sea conveniente- que algunas de las citas referidas de Ortega reproducidas en el presente trabajo son citadas según el criterio y fuente bibliográfica manejada en ese momento por el propio García Bacca. ${ }^{2}$

Así pues, sin una correcta comprensión de la génesis de la propuesta metafísica garcibacquiana resulta imposible, a nuestro parecer, una correcta comprensión del propio sentido y devenir del método dialéctico transustanciador propuesto por García Bacca hacia finales de los años 60 del pasado siglo. Si bien nosotros no entraremos en el presente artículo a analizar esta y otras cuestiones - por una evidente falta de espacio-, si atenderemos a una cuestión muy concreta y clave para comprender el nacimiento de una propuesta metafísica generalmente desconocida e ignorada por gran parte de la academia filosófica española. En este sentido, nuestro trabajo pretende ser una suerte de manifiesto sobre la importancia tanto de la obra, así como de la vida de Juan David García Bacca, filósofo español y exiliado que, sin lugar a dudas, bien merece su espacio y reconocimiento dentro del panorama filosófico español y latinoamericano.

\footnotetext{
${ }^{2}$ Con el fin de evitar posibles confusiones de carácter histórico y cronológico respecto a las obras completas de Ortega y Gasset, nosotros haremos uso de la misma que el propio García Bacca empleó para sus trabajos sobre Ortega. Si bien somos plenamente conscientes de la reactualización y revisión de las obras completas de Ortega, no es menos cierto que la inclusión por nuestra parte de las obras completas de Ortega en el presente trabajo puede contribuir a un desfase hermenéutico que, en cualquier caso, hemos tratado de evitar en la medida de lo posible. Por esa razón, nosotros haremos uso exactamente de la misma referencia bibliográfica que García Bacca emplease para la elaboración de sus escritos. De ese modo, creemos que es posible evitar una discusión crítica fuera del tiempo y el contexto propio de García Bacca respeto algunos aspectos propio de la obra de Ortega. En la biblioteca de Navarra (Pamplona) se encuentra gran parte de la biblioteca personal de García Bacca. Según nosotros mismos pudimos comprobar, la edición empleada por García Bacca respecto a las obras completas de Ortega es la siguiente: ORTEGA Y GASSET (1943).
} 
Por todo ello, el artículo que a continuación presentamos pretende dar a conocer el sentido y origen de una propuesta metafísica que, tal y como creemos demostrar, surge de una visión crítica respecto de los supuestos metafísicos orteguianos.

2. EL PESO DE LA HERMENÉUTICA HISTORICISTA Y EL RATIOVITALISMO DE ORTEGA.

Como tendremos ocasión de comprobar a lo largo del presente artículo, García Bacca desarrollará su inicial programa metafísico sobre la base de lo que Ortega $^{3}$ da a conocer como metahistoria, una nueva disciplina filosófico científica en la que el acento principal recae en los flujos históricos de las ideas que, a juicio de Ortega -y a diferencia del materialismo histórico-, son las que moldean y dan forma a la racionalidad de cada época histórica.

Así se explica Ortega sobre el propósito de su plan hermenéuticohistoricista que tanto influyó en el inicial proyecto metafísico garcibacquiano:

"La idea de que todo influye en todo, de que todo depende de todo, es una vaga ponderación mística que debe repugnar a quien desee resueltamente ver claro. No; el cuerpo de la realidad histórica posee una anatomía perfectamente jerarquizada, un orden de subordinación, de dependencia entre las diversas clases de hechos. Así, las transformaciones de orden industrial o político son poco profundas: dependen de las ideas, de las preferencias morales y estéticas que tengan los contemporáneos. Pero a su vez, ideología, gustos y moralidad no son más que consecuencias o especificaciones de la sensación radical ante la vida, de cómo se sienta la existencia en su integridad indiferenciada. Esta que llamaremos sensibilidad sentimental, es el fenómeno primario en historia y lo primero que habríamos de diferenciar para comprender una época". (ORTEGA Y GASSET 2005, p. 61).

Es decir, en primera instancia, evidenciamos la idea de que la historia mantiene un pulso de cambio y transformación consigo misma. Pulso vital de cambio que, como podremos comprobar, es crucial en García Bacca no sólo al inicio de su proyecto metafísico sino que, de alguna manera, atravesará no sin transformaciones, correcciones y ajustes, el conjunto histórico-vital del proyecto metafísico garcibacquiano. La propuesta de Ortega se basa en una

\footnotetext{
${ }^{3}$ Cfr. AbelLán (1966). Véase también Marías (1960).
} 
autoevidencia, a saber, el hecho de que la historia en su conjunto queda sometida al cambio y la transformación permanente.

Cambio y transformación que, a falta de mayor análisis por parte de García Bacca queda, sospechosamente, a nuestro entender, asentada sobre algo tan primario y primero como es la sentimentalidad vital. Si esto es así, entonces se hace comprensible la propuesta de Ortega de una metahistoria, es decir, un estudio de los ritmos o pulsaciones de la historia del hombre bajo la atención, claro está, de la sensibilidad sentimental. Ortega anuncia del siguiente modo el interés por desarrollar dicha metahistoria: "La razón de esta inadvertencia está en que no se ha intentado aún formalmente la instauración de una nueva disciplina científica, que podría llamarse metabistoria, la cual sería a las historias concretas lo que es la fisiología a la clínica”. (ORTEGA Y GASSET 2005, p. 65)

$\mathrm{Y}$ es que, como se podrá comprobar más adelante, las bases iniciales del proyecto metafísico garcibacquiano se basan, a nuestro parecer, en la posibilidad de desarrollar de modo práctico la metahistoria propuesta por Ortega, es decir, en las posibilidad de desentrañar -a posteriori-, la racionalidad vital que determina cada época histórica. La metahistoria es posible, a juicio de Ortega, precisamente porque la vida, esto es, aquello que rige y sostiene la existencia humana en sus bases ontológicas sigue una racionalidad de leyes aún sin determinar. Leyes que dan cabida al azar dentro de la facticidad humana; no así en las propias bases o fundamentaciones ontológicas. De otro modo, en opinión de Ortega la vida queda sostenida por ciertas leyes que hacen posible el estudio de la historia desde la perspectiva de la ciencia. Así se explica el propio Ortega: "Por ser la existencia humana propiamente vida, esto es, proceso interno en que se cumple una ley de desarrollo, es posible la ciencia histórica. A la postre, la ciencia no es otra cosa que el esfuerzo que hacemos para comprender algo. $\mathrm{Y}$ hemos comprendido históricamente una situación, cuando la vemos surgir necesariamente de otra anterior". (ORTEGA Y GASSET 2005, p. 71)

Es decir, al parecer existe un conjunto de leyes que regulan o sostienen el conjunto de la vida del hombre. Vida entendida e interpretada como el conjunto de procesos internos de pensamientos y sentimientos que darían, en el supuesto de poder acceder a dichas leyes o principios, una cierta rigurosidad a la hora de poder establecer una ciencia que centre su atención en la historia misma. De otro modo, para Ortega es posible una ciencia de la historia porque la vida -conjunto de procesos internos-, cumple y sigue una serie de supuestas leyes de desarrollo. Si esto es así, entonces, sería posible establecer con 
rigurosidad científica el conjunto de leyes que sustentan la racionalidad de cada época y de cada generación histórica.

Bajo el amparo de esta tesis respecto a la identificación de las supuestas leyes encargadas de regular la racionalidad histórica, creemos que Ortega está intentando asentar las bases de una revisión profunda de los fundamentos metafísicos-ontológicos que sustentan el desarrollo cultural del hombre. Cultura que nace de modo espontáneo y subjetivo pero que, con el tiempo, la propia actividad racional del hombre deriva en objetividad y normatividad. Dicha normatividad contribuye a que la cultura se anquilose por una razón histórica y antropológica, a saber, el hecho de que el hombre ha abandonado el principio de vitalidad. ${ }^{4}$

Si esto es así, la cultura no sólo queda regida por ciertas leyes o principios racionales que derivan en una pérdida de identidad del hombre sino, también, en una dualidad formada por los pares "cultura-hombre" y por el imperativo "social-vitalidad" subjetivo que condena al fracaso a la propia cultura. De otro modo, Ortega está, a nuestro juicio, diagnosticando el mal que recorre y degenera a la cultura y la sociedad: "De pronto la obligación de ser leales consigo mismos, de decir si creían de manera auténtica en lo que creían. Y han descubierto que no. A este descubrimiento han llamado fracaso de la cultura. Claro es que no hay tal: lo que había fracasado mucho antes era la lealtad de los europeos consigo mismos: lo que había fracasado es su vitalidad" (ORTEGA Y GASSET 2005, p. 96).

Según interpretamos nosotros a partir de las palabras de Ortega, pensamos que el fracaso de la cultura se sustenta principalmente en el abandono de la dimensión vital por parte del hombre. ${ }^{5}$ Si esto fuera así, entonces, a nuestro juicio, el principio de vitalidad orteguiano es, de algún modo, una categoría crucial en el desarrollo iniciático del programa metafísico garcibacquiano. Y es que, al parecer, la idea fundamental que sustenta la obra de Ortega El tema de nuestro tiempo, así como los primeros años del programa metafísico desarrollado por García Bacca, se asientan en el restablecimiento de la razón vital como eje sobre el cual se dan las condiciones optimas para que, en opinión de los dos

${ }^{4}$ Para mayor información sobre el concepto orteguiano de vitalidad véase ORTEGA Y GASSET (2004).

${ }^{5}$ No entendido como fracaso teórico sino, más bien, desde un orden de nivel fáctico y ontológico. 
filósofos españoles, se desarrolle y despliegue a posteriori la razón pura, y no a la inversa.

Es decir, la razón pura, con su conjunto de categorías, axiomas, leyes y principios en sí han intentado, irónicamente, desplazar y marginar la dimensión pura y absolutamente espontánea de la Vida. Para Ortega y García Bacca la cultura -si quiere seguir manteniendo su legitimidad- debe, por el peso que determina el sentido común de la propia vida, vindicar para sí el propio sustento de la Vida humana en su carácter de espontánea, y no encerrarla ni encorsetarla en los márgenes -más estrechos que amplios- de la razón pura.

Según nosotros interpretamos, para Ortega la cultura y la sociedad en Europa ha derivado en un cuello de botella en la que la razón pura, que se tenía por desatascador o abridor de los defectos sociales, políticos, morales, etc., ha terminado convirtiéndose en una suerte de tapón. Únicamente una inversión en las lógicas y razones - de pura a vital-, darán salida al flujo espontáneo de la propia vida del hombre y, por lo tanto, de la cultura misma. Así se explicaba Ortega en su obra El tema de nuestro tiempo:

"La razón pura no puede suplantar a la vida: la cultura del intelecto abstracto no es, frente a la espontánea, otra vida que se baste a sí misma y pueda desalojar a aquella. Es tan sólo una breve isla flotante sobre el mar de la vitalidad primaria. Lejos de poder sustituir a esta, tiene que apoyarse en ella, nutrirse de ella, como cada uno de los miembros vive del organismo entero". (ORTEGA Y GASSET 2005, p. 103)

Es decir, la categoría esencial en la reformulación ontológica de la metahistoria propuesta por Ortega es, sin duda alguna, la razón vital o, del mismo modo, la propia categoría de la Vida como, en el caso de García Bacca, surtidor espontaneo de sentimentalidades. ${ }^{8}$

\footnotetext{
6 Para mayor información sobre el concepto de "razón pura” véase KANT (2006).

7 El término "espontáneo" tiene una importancia relevante en la obra de García Bacca, especialmente en la $4^{\circ}$ etapa de su pensamiento. Para mayor información sobre el categoría de espontáneo en la obra de García Bacca véase GARCíA BACCA (1985).

${ }^{8}$ La idea de que el hombre es un surtidor espontáneo de novedades, -jaillissement de nouveautéso, como en este caso de sentimentalidades, la toma García Bacca de BERGSON (1907). La idea de que el hombre es un "surtidor espontáneo de novedades" es de las pocas tesis metafísicas que, desde el inicio de su propuesta metafísica, hasta su última obra publicada en vida, mantendrá García Bacca de modo invariable. Respecto a la referencia para una mayor profundización en la figura e importancia de Bergson en el pensamiento garcibacquiano destacamos la obra del filósofo español GARCía BACCA (1947; nueva edición en 1990). El
} 
Como se podrá comprobar, el concepto de Vida orteguiano -como sustento y soporte de la racionalidad pura constituye uno de los elementos cruciales en la génesis de los planteamientos metafísicos y ontológicos garcibacquianos. Veremos más adelante en qué medida, y hasta que punto, el término Vida es capital en el pensamiento de García Bacca. Baste, por el momento, recordar las palabras del propio Ortega referidas al tema central de nuestro tiempo: "El tema de nuestro tiempo consiste en someter la razón a la vitalidad, localizarla dentro de lo biológico, supeditarla a lo espontáneo" (ORTEGA Y GASSET 2005, p. 104).

\subsection{PRIMERAS REFERENCIAS GARCIABACQUIANAS SOBRE LA OBRA DE ORTEGA.}

Expuesto desde las fuentes orteguianas el fundamento que sostiene el tema de nuestro tiempo se hace crucial, en este punto de nuestro trabajo, introducir lo expuesto y desarrollado por el propio García Bacca a propósito de los principales principios metafísicos y ontológicos de Ortega. Para ello, haremos uso de los que, a nuestro juicio, son los textos más importante y significativo sobre el pensamiento de Ortega escrito por García Bacca. ${ }^{9}$

En primer lugar, nos referiremos a la $8^{\circ}$ lección sobre Nueve grandes filósofos que García Bacca dedicará a la figura de Ortega y Gasset. ${ }^{10}$

Nueve grandes filósofos es publicado por primera vez en 1947 pero, muy probablemente, García Bacca los escribe entre los años 1943 y 1944. Según nos advierte García Bacca ya en el prologo a la reedición en Anthropos de 1990, el texto reeditado fue concebido como unas clases para la universidad de México en el año 1944: "En esa edición primera, advertirá el Lector que el texto es redacción de un curso que dio el Autor a un auditorio. De persona a persona. Curso dictado en la Universidad de Nuevo León, Monterrey, México, en 1944” (GARCía BACCA 1990, p. 7). Sea como fuere, las opiniones y juicios de García Bacca sobre la obra de Ortega deben datarse, como mínimo, a mediados de los años 30 del pasado siglo y, como máximo, hasta la elaboración de sus lecciones

texto es publicado en 1947, pero García Bacca los escribe muy posiblemente entre los años 1943 y 1944. Según el propio filósofo español advierte en el prólogo a la reedición de 1990, el texto reeditado fue concebido como unas clases para la universidad de México en el año 1944.

${ }^{9}$ En especial, nos referiremos al apartado que García Bacca dedica a la obra de Ortega El tema de nuestro tiempo (GARCÍA BACCA 1990a, pp. 343 y ss.).

${ }^{10}$ GARCía BACCA (1947). Nosotros haremos uso de la nueva edición aparecida en 1990 en Anthropos. 
sobre Ortega redactadas entre los años 1943 y 1944. Como se comentó anteriormente, la principal referencia bibliográfica sobre Ortega empleada por García Bacca son las obras completas editadas en Espasa Calpe publicadas en 1943.

Si destacamos este hecho cronológico e histórico es porque en 1947, la imagen que García Bacca tiene de los fundamentos y principios orteguianos no es, ni de lejos, los mismos que los expuestos y desarrollados durante los año 43 y 44. No decimos que en el año 47 -año de publicación de su obra Nueve grandes filósofos-, García Bacca haya mutado o evolucionado de un ratiovitalismo orteguiano exacerbado a, pongamos por caso, una fidelidad incondicional hacia los supuestos heideggerianos. Pero sí es cierto que, durante los últimos años de la década de los años 40 del pasado siglo, se empieza a observar un principio difuso de cambio y transformación progresivo de los fundamentos metafísicos garcibacquianos que, de modo irremediable, se alejan cada vez más del raciovitalismo orteguiano.

Advertido este hecho, centrémonos en el sentido y valor de lo expuesto por García Bacca sobre la vida y obra de Ortega porque, de algún modo, la extensísima lección que García Bacca dedica en su obra Nueve grandes filósofos sobre la filosofía de Ortega constituye, en sí misma, una especie de manifiesto teórico no sólo sobre la filosofía de Ortega sino que, de algún modo, puede interpretarse como un reconocimiento por parte del propio García Bacca sobre lo que del pensamiento de Ortega hay en su propio esquema metafísico.

\section{LECCIÓN MONOGRÁFICA SOBRE ORTEGA}

La lección que García Bacca le dedica a Ortega está programada y dividida en tres partes, a saber:

a) Estratigrafía entitativa o lógica.

b) Estratigrafía vital general.

c) Sismografía vital o bistoria de la vida.

La principal intención de García Bacca en la lección dedicada a Ortega en Nueve grandes filósofos pasa, esencialmente, por desarrollar los fundamentos de un nuevo enfoque filosófico. Este nuevo enfoque filosófico tiene que ver, tal y como se podrá comprobar, con el principio de razón vital orteguiano.

A nuestro juicio, lo que fascina realmente a García Bacca de este novedoso principio introducido y planteado por Ortega es, esencialmente, la idea de 
oponerse con solidez y rigurosidad a una historia de la filosofía y del pensamiento que, según nosotros interpretamos, Ortega ha autoconsumido en sus propias posibilidades puramente racionales o relativistas. Si esto es así, pensamos que el nuevo enfoque metahistórico orteguiano permite asentar -no de modo rotundo ni definitivo-, una nueva forma de estratificar y ordenar la existencia humana. Un nuevo enfoque que García Bacca empleará como acicate de su inicial propuesta metafísica.

Como podremos comprobar, el tercero de los puntos de la lección que García Bacca le dedica a Ortega en Nueve grandes filósofos se centra en las posibilidades que abre el nuevo modelo organizador y estratificador vital. Modelo que debe ser explotado en sus posibilidades ya que, de establecerse de modo práctico, sería viable el desarrollo fenomenológico-hermenéutico de un principio fáctico de los propios cambios histórico-existenciales acaecidos en el ser y en el mundo.

De otro modo, si no existen esencias determinantes, es decir, si el hombre se siente creador del conjunto de valores sociales, políticos, económicos, morales y religiosos, entonces, decimos, es posible considerar la posibilidad de que el hombre pudiera intervenir en ellos reformándolos o, simplemente, renunciando a ellos.

Si esto es así, es posible que la historia vital sea interpretada o bien como el análisis de la posibilidad de los cambios - en un futuro a modo de pronóstico emocional y vital-, o como una hermenéutica de los cambios producidos en el hombre y la propia sociedad en la que está inmerso. Sociedad de la cual, a juicio del propio García Bacca, el hombre participa activamente creando, generando e inventado nuevos valores o, simplemente, afiliándose a ellos de modo perpetuo. Pasemos, pues, al primero de los puntos de dicha lección.

\subsection{ESTRATIGRAFÍA ENTITATIVA O LÓGICA}

García Bacca sostiene que, a propósito del cambio de paradigma respecto al orden de las razones existentes introducido por Ortega, será la razón vital la escogida para hacerse cargo del propio programa y desarrollo de las ciencias modernas. Ciencias guiadas por un nuevo paradigma de razón pura:

"No son la razón pura ni la razón histórica siquiera las que descubren el verdadero programa de una ciencia pura, ciencia en sí de los objetos, sino la razón vital consciente de sí es la que sabe separar tales instrumentos que la razón pura y la histórica habían considerado, y aun vivido como suyos por haberse comprometido, irreflexivamente, iquién lo dijera!, con los objetos. La 
razón vital es, pues, más objetiva, más objetivante u objetivadora que la razón pura y la histórica" (GARCíA BACCA 1990, p. 300).

Si esto es así, para García Bacca la razón vital tiene un grado de objetivación mayor que el de la razón histórica o pura respectivamente. Lo tiene, porque es la razón vital $-\mathrm{y}$ no otra-, la que tiene, al modo hegeliano, un mayor grado de autoconciencia de sí misma. ${ }^{11}$

Hasta la irrupción y desarrollo de las nuevas ciencias, así como el planteamiento y despliegue filosófico del enfoque orteguiano de la razón vital, se creía que la razón pura constituía la estructura misma de la física ${ }^{12}$. Si esto es así, es posible interpretar que la razón pura -y el conjunto de las categorías-, actúen como las condiciones de posibilidad para el despliegue intelectual de las propias ciencias; incluso de la experiencia misma.

Con la irrupción y desarrollo orteguiano de la razón vital -así como de las nuevas ciencias-, se pone en jaque el paradigma ilustrado de la razón y se abre, al mismo tiempo, nuevas posibilidades interpretativas que apoyan argumentativamente la idea de que entre la física, las matemáticas y la propia conciencia, existe una distancia que sostiene y mantiene la autonomía de las cosas. Es decir, que no será la razón pura la que constituya en sí la propia física o matemática, ni siquiera el objeto mismo:

"La física moderna en la forma dicha, es un efecto de la razón vital que ha conseguido separar la ciencia física de su intromisión en la razón histórica, intromisión grande aún, y libertarse y libertarla de la unión, casi orgánica, que la misma ciencia física tenía con la razón pura y que Kant, cándidamente, había creído ser nada menos que la sustancia categorial de la razón misma. Es decir: para la razón pura la estructura de la ciencia física es estructura de la razón misma, órgano suyo, condiciones de posibilidad de los objetos de la experiencia (Kant). Todo esto ha sido refutado no por los filósofos, idólatras

\footnotetext{
11 Según nosotros entendemos, la razón pura e histórica son dos razones de mayor especificación y especialización, es decir, su grado de autoconciencia no les permite tomar perspectiva objetiva u objetivadora sobre el programa de desarrollo científico o técnico en el que desarrollan su potencial como racionalidades. Esta perspectiva genera, como así pretende sostener Ortega y García Bacca, la idea de que existen estratos en los grados de racionalidad y que, a diferencia de lo sostenido históricamente en la filosofía occidental, existe una racionalidad más amplia, objetiva y general -razón vital-, que está muy por encima en el grado de objetivación y autoconciencia del resto de sustratos racionales existentes y configuradores del hombre.

${ }^{12}$ Cfr. KANT (1997).
} 
de la razón pura -que ahora resulta ser demasiado razón vital, vida comprometida con la física clásica, lo que ella no es-, sino por la física moderna. (...) la ciencia gana en pureza, y en eficacia, cuando la construye la razón vital, poniéndola a máxima distancia de sí y de la inteligencia contemplativa, intuitiva...; y pierde en pureza científica y en eficacia cuando, ¡quien lo dijera!, la construye la razón pura" (GARCÍA BACCA 1990a , p. 305).

Es decir, para García Bacca, la ciencia moderna gana en objetividad y valor cuando la razón vital tiene conciencia del propio programa y plan de las ciencias. Todo esto tiene que ver, a nuestro juicio, con el grado de autoconciencia que posee la razón vital que, desde la atalaya de la conciencia de sí, puede desprenderse y despegarse de la fusión infructuosa y canónica entre razón pura y ciencia.

Pero, la desmantelación y anulación del señorío y poderío de la razón pura a manos de los nuevos avances de la ciencia, así como el desarrollo de la razón vital no queda reducido únicamente a la autonomía de las ciencias sino que, también, afecta a la noción de categoría a priori. En este caso -la razón pura-, al dejar de ser estructura y condición de posibilidad del conocimiento, así como estructura de las propias ciencias. Del mismo modo, ha dejado de constituirse bajo principios universales y categorías. Según este cambio de paradigma respecto el poderío ejercido históricamente por la razón pura sobre cualquier otro tipo posible de racionalidad, la razón vital impone el valor de las hipótesis respecto a las clásicas categorías. Así lo explica el propio García Bacca:

"Digamos en toda su generalidad: entre el núcleo a priori de una ciencia y los hechos observables no hay continuidad ni paso de universal a particular, sino hipótesis, en el caso de la física, postulado de funciones propias correspondientes a valores propios.

Lo matemático y lo lógico han dejado de ser condiciones de posibilidad de la experiencia, es decir: categorías constitutivas del entendimiento. Con lo cual la vida, mediante la razón vital, se ha sacado del cuerpo, de la vida, esa espina de lo lógico y lo matemático, lo formal, que desde Descartes se le había ido hincando cada vez más” (GARCÍA BACCA 1990a, p. 309).

Con el fin de poder asentar progresivamente la exposición sobre la influencia de Ortega en la gestación y nacimiento del proyecto metafísico garcibacquiano durante los primeros años de la década de los 40 de siglo pasado, atendamos al segundo de los puntos de la lección sobre Ortega que García Bacca dedica en su obra Nueve grandes filósofos. 


\subsection{ESTRATIGRAFÍA VITAL GENERAL.}

El cambio de paradigma ontológico introducido por Ortega en el seno de la discusión académica tradicional es de tal magnitud, que el nuevo enfoque metafísico se basa, esencialmente, en otorgar el protagonismo central ontológico no al ser -pues todo enfoque ontológico tradicional se basa en la pregunta por el ser- sino que, en contra de lo comúnmente establecido, el cambio de enfoque pasa por ceder la totalidad argumentativa al concepto de vida y al tipo de razón que la regula.

A nuestro juicio, tanto para Ortega así como para García Bacca, la razón vital se convierte en el eje del nuevo programa ontológico. Para que dicho cambio de paradigma ontológico se produzca, es necesario basar la argumentación bajo un supuesto existencial muy concreto, a saber: que el hombre adquiera conciencia de su propia existencia vital como hombre -cosa y ente-. Es decir, que el hombre, en tanto que arrojado en el mundo con otros y siendo, a su vez, una de tantas cosas en el mundo, el hombre se haga cargo de sus circunstancias. ${ }^{13}$

Si esto es así, es plausible pensar que tanto para Ortega, así como para García Bacca, el hombre posee una conciencia de su realidad como viviente previa a la razón trascendental y pura. Sentencia el propio García Bacca al más puro estilo orteguiano: "Por tanto: ser se dice primeramente de vida bumana, por ser la única realidad misma nos está siendo conscientemente dada; pero también nos está siendo conscientemente dado que nuestra vida es circunstanciada" (GARCíA BACCA 1990a, pp. 318-319).

Pensamos que el nuevo modelo ontológico propuesta por Ortega y defendido por García Bacca, bien puede generar y suscitar cierta cuestiones que aquí nos atrevemos simplemente a formular. Así pues, si el hombre es una cosa en el mundo, ¿dónde y en qué lugar está el ser de dicho hombre? ¿es el hombre entendido como cosa el nuevo paradigma central del proyecto ontológico orteguiano? De alguna manera sí y no. Veamos por qué y en qué medida.

\subsubsection{SER Y ENTE COMO COSA VIVIENTE, GARCÍA BACCA Y EL REAJUSTE CATEGORIAL}

${ }^{13}$ Para mayor información sobre el concepto de "circunstancia" en Ortega véase ORTEGA Y GASSET (2004). 
A nuestro parecer, el hombre y su realidad circunstanciada constituye, en gran medida, el centro de la nueva propuesta ontológica orteguiana. El hecho de ubicar al hombre y sus circunstancias como nuevo centro de la reflexión metafísica puede generar ciertas suspicacias que deben ser debidamente atendidas pues, ¿qué sentido tiene remplazar la idea de Dios del cual el resto de seres participan por analogía, por la imagen de un hombre -sustituto de dios-, del que todas las cosas y objetos participan?

En este caso, la respuesta de García Bacca a dicha cuestión pasa, esencialmente, por atribuir al hombre de carne y hueso la capacidad de saberse como uno en el mundo con el resto de cosas. Podríamos decir que, al igual que ocurre en el caso de la propuesta fenomenológica heideggeriana, el hombre de carne y hueso propuesto por Ortega hace referencia al término Ente. ${ }^{14}$

El mundo está lleno, repleto y rebosante de entes. El hombre es un ente más pero con una peculiaridad que lo distingue del resto, a saber, es el único que puede interrogarse a sí mismo en busca de su ser. Esta característica especial no lo disuelve como ente, sino que, al contrario, lo reafirma como tal. Lo esencial del asunto es que, desde su capacidad interrogativa, el ente, es decir, el hombre de carne y hueso, es capaz de hacer ontología, o lo que es lo mismo, puede describir e interpretar el ¿de dónde? y ¿cómo es? el ser que lo constituye como ente.

Si la cuestión ontológica primera es desentrañar de dónde procede o se genera el concepto de ser -en el caso de Ortega-, García Bacca lo parece tener claro. Al parecer, en un momento concreto de la historia, el hombre tendió al ensimismamiento, o lo que es lo mismo, a encerrarse en sí mismo en busca de las ideas que lo constituyen como ente. Dice García Bacca al respecto: "Afirmación de la posibilidad radical del hombre de ensimismarse. Aquí surgen las ideas y en especial la del ser que es desinteresarse, desalterarse de todas las

\footnotetext{
14 Por Ente, pensamos en el descrito por Heidegger en su obra Ser y tiempo. Un Ente distinto de la concepción clásica y generalista de la metafísica clásica que lo había disuelto junto a la idea o concepto de Ser. Es sabido que, a partir de Heidegger y su revisión de los términos Ser y Ente en su obra Ser y tiempo, ambos conceptos pasan a ser cosas distintas. El Ente pasa a ser cualquier cosa y, en el caso del hombre, recibe el nombre genérico de Dasein. La clave del proyecto fenomenológico de Heidegger en el momento de la publicación de Ser y tiempo pasa por describir cuál y cómo es el Ser del Dasein. Por lo que a nosotros respecta en este punto, únicamente nos interesa asociar dicha distinción ontológica entre Ser y Ente llevada a cabo por Heidegger y tenerla presente en todo momento.
} 
cosas especiales, por reales que sean en sí. Ontología genética" (GARCíA BACCA 1990a, p. 316).

A nuestro parecer, García Bacca recupera el concepto de "ensimismamiento" de la obra de Ortega Ensimismamiento y alteración que, hasta en tres ocasiones, García Bacca cita en su lección dedicada al filósofo español. El fragmento de la obra de Ortega citado por el propio García Bacca dice:

"Son, pues, tres momentos diferentes que cíclicamente se repiten a lo largo de la historia humana en forma cada vez más compleja y densa: 1 . El hombre se siente perdido, náufrago en las cosas: es la alteración. 2. El hombre, con un enérgico esfuerzo, se retira a su intimidad, para formarse ideas sobre las cosas y su posible dominación; es el ensimismamiento, la vita contemplativa, que decían los romanos, el theoretikos bios de los griegos, la teoría. 3. El hombre vuelve a sumergirse en el mundo, para actuar en él conforme a un plan preconcebido: es la acción, la vita activa, la praxis (ORTEGA Y GASSET 1943a, p.1535).

En este caso García Bacca nos recuerda, a propósito de las palabras de Ortega, que el origen de la idea de ser surge como segundo paso en la historia misma del proceso existencial del hombre, es decir, el del ensimismamiento. En opinión de García Bacca, del estado de ensimismamiento surge, pues, el naufragio y la confusión de estar en mitad del mundo y descubrirse a sí mismo como hombres de carne y hueso.

Aún así, es decir, a pesar de que el origen de la autoconciencia inicial del hombre como ente de carne y hueso se produzca a propósito del ensimismamiento, no por ello la condición existencial del ente entendida como eyectado o arrojado -perdido en el mundo con otros y otras cosas-, crea por sí misma la idea de ser. Es necesario que el ente vuelque sobre el mundo la noción de ser con la intención de poner sobre el tapete de la realidad entificada del mundo, lo que nació como mera idea y respuesta a una pérdida u olvido existencial. Pérdida u olvido que se espera, se resuelva con un esquema ontológico renovador. Por eso, García Bacca afirma a propósito del tercer paso en el esquema orteguiano:

"Afirmación de que el ensimismamiento está siendo acechado y tentado por las cosas; y por tanto las ideas y la del ser tienen que volver a aplicarse a las cosas, Son proyectos de nuevos tipos de trato con ellas. Ontología aplicada, válida. 
Aplicar la idea de ser, obtenida en ensimismamiento, producida en inventada por el sujeto en sí, es, con el término clásico, ponerla en el mundillo de las cosas para que éstas aparezcan cual seres, en forma ya de mundo" (GARCía BACCA 1990, p. 323).

Es decir, de un modo más claro: para García Bacca, el proyecto ontológico de Ortega pasa, en un primer momento, por tratar de encontrar un origen a la idea misma de ser. Sabemos que dicha idea surge de un ente que, bajo la premisa ontológica de estar arrojado al mundo como ente, esto es, como uno de tantos, está capacitado no sólo para interrogarse a sí mismo sobre el ser que lo caracteriza como ente-hombre sino que, también, es el único capaz de hacerlo.

Si esto es así, el hombre de carne y hueso está absolutamente legitimado para sostener un nuevo paradigma ontológico en el que, a diferencia de lo visto lo largo de la historia de la filosofía occidental -a excepción de Heidegger-, el ente-hombre es el foco y centro del nuevo discurso ontológico. Para Ortega y García Bacca, el ente circunscrito y circunspecto al mundo ${ }^{15}$ de cosas y entes tiende a ensimismarse, esto es, generando, inventando y proyectando posteriormente el compendio de ideas -como la de ser-, al mundo en el que vive y en el que encuentra las circunstancias que lo determinan y constituyen como hombre de carne y hueso.

En resumidas cuentas: para ambos filósofos españoles, el ente en su estado de ensimismado pasa a ser el nuevo centro del proyecto ontológico. García Bacca lo expone con rotunda claridad: "El concepto de ser, tal como lo inventa la vida en ensimismamiento, no es de universalidad uniforme, no es unívoco. Se dice - pues surge- primariamente del Hombre, y del Hombre en fase de ensimismamiento; y secundariamente de las cosas" (GARCíA BACCA 1990, p. 324).

\footnotetext{
${ }^{15}$ Como ocurrió con el caso de los conceptos Ser y Ente que quedaban remitidos y asociados a la obra de Heidegger, igual ocurre con el concepto de mundo. Concepto que nos remite a la idea de circunstancia orteguiana y que queda asociado, del mismo modo, a las idea de inmediatez. El mundo es lo que nos rodea ahora mismo y en todo momento. Es aquello que configura nuestras circunstancias fácticas más inmediatas. En el caso de García Bacca, la noción de mundo será central a partir de los primeros años 60 del pasado siglo. Para mayor información sobre la noción de mundo en García Bacca véase GARCíA BACCA (1963).
} 
Es decir, el hombre inventa ${ }^{16}$ el concepto e idea de Ser. El hombre, con toda su circunstancia existencial de ente arrojado, inventor y creador de novedades, es decir, como centro y eje de su existencia circunstanciada es, como se ha repetido hasta la saciedad, el centro de todo proyecto ontológico.

\subsection{SISMOGRAFÍA O VULVANISMO VITAL}

La idea de que para Ortega -y especialmente durante el inicio de la $3^{\circ}$ etapa garcibacquiana-, la razón vital esté por encima de la razón histórica y de la razón pura queda reflejado y explicado en este tercer sismo que presentamos a continuación.

La razón vital propuesta y desarrollada por Ortega y asumida por García Bacca, la razón más propia y radicalmente intrínseca al hombre. Si el hombre prioriza la razón vital respecto a la razón pura, el ente es capaz de tomar conciencia de sí como hombre circunscrito en un mundo repleto de otros hombres. Mundo en el que cada ente se debe a sus propias circunstancias. La idea relativamente revolucionaria de Ortega -a juicio de García Bacca-, es la graduación de los tipos de razones existentes que, en su sentido más radicalmente humano, pasa por advertir que la razón vital propuesta por Ortega posee, como principal característica, la de contribuir activamente a que los hombres, desde su estado existencial de individualidad de la pluralidad del mundo y de cosas que lo forma, tomen conciencia de sí como sujetos eyectados en el mundo y en sus propias circunstancias de las que debe hacerse cargo y tratar de salvar. La razón vital es, pues, la forma a través de la cual, el hombre arrojado al mundo plural y múltiple, se le aparecen las cosas de las que participa como una de tantas y, al mismo tiempo, es capaz de alcanzar un grado de autoconciencia que lo habilita ontológicamente como ente.

Si esto es así, tanto para Ortega así como para García Bacca, la razón pura queda desplazada hasta tomar el lugar que le corresponde, es decir, ser la encargada de generar un sistema concreto y determinado de principios de corte universal. Desde dichos principios de corte universal, el mundo se le aparece al ente como determinado, fijo y estable. Puede decirse, pues, que para Ortega la razón pura siempre quedará subyugada bajo el dominio de la razón suprema

\footnotetext{
${ }^{16}$ Los conceptos de creación y de invención serán de crucial importancia para el desarrollo ontológico de García Bacca. Son conceptos que quedan asociados a la expresión garcibacquiana de: "surtidor de novedades" y que el filósofo español toma del filosofo francés H. Bergson.
} 
que hace de sustento de la propia vida del hombre, a saber, la razón más inmediata; la razón vital. García Bacca expone del siguiente modo estas ideas generales sobre el fundamento ontológico original de Ortega:

“1.1) por la que la vida excéntrica, que es la que se halla excéntrica o fuera del orden de la realidad indeterminada y del orden de lo posible, elige para sí una de las posibilidades o sistemas de ordenaciones, como las llama Ortega, y hace de ella plan o proyecto. (...) 1.2) Por tanto: no selecciona la vida pura y simplemente una de las posibilidades, sino que, además, hace de ellas proyecto o plan objetivo; lo impone a las cosas, obligándolas (...) a que le respondan con respuesta objetiva, con especial aparición correspondiente al plan concreto que la Vida les propone, dejando a la realidad de aparecerse a otros programas de posibilidad que la vida no ha tomado en aquel momento histórico" (GARCíA BACCA 1990, p. 374).

Es decir, para García Bacca la razón pura ha optado -en un grado de inconsciencia-, por un determinado sistema de principios posibles indeterminados-. Del mismo modo, la razón histórica puede hacer recuento de la historia misma de las ideas que la razón pura ha empleado a lo largo de la historia del pensamiento. Pero, por encima de esta historiografía, la razón vital orteguiana sabe y toma conciencia de que, de hecho, los multiversos ${ }^{17}$ posibles entre los que podría desarrollar su existencia - diferentes universos, con diferentes principios- son, en esencia, tantos como el hombre sea capaz de asumir y poner en práctica. Para García Bacca, el hombre escoge entre diferentes posibilidades, sistemas y principios con los que deja que el mundo se le muestre. En definitiva, y con las propias palabras de Ortega:

"Ni se deja traspasar sin más ni más por ella, como acontecería al imaginario entre racional creado por las definiciones racionalistas, ni finge él una realidad ilusoria. Su función es claramente selectiva. De la infinitud de los elementos que integran la realidad, el individuo, aparato receptor, deja pasar un cierto número de ellos, cuya forma y contenido coinciden con las mallas de su retícula sensible. Las demás cosas -fenómenos, hechos, verdades- quedan fuera, ignoradas, no percibidas" (ORTEGA Y GASSET 1943b, p. 667).

La idea de que existen diversos grados de conciencia y uso de la razón razón pura, histórica y vital- configuran, en sí, el propio sistema ontológico y epistemológico del hombre propuesto por Ortega y, en cierto grado, asumido

${ }^{17}$ El empleo del término multiverso es una licencia nuestra para referirnos a la idea de universos paralelos. Dicho término fue acuñado por el psicólogo William James en 1895. 
por García Bacca. Según lo expuesto hasta el momento, sabemos que el hombre está inevitablemente circunstanciado en el mundo de cosas. Sabemos, también, que las cosas se nos muestran a través de la razón pura en un sistema ideal determinado para el hombre. Igualmente, se ha comentado que dichos sistemas que abren al hombre ante la presencia de las cosas entendidas como ideas universales terminan, irremediablemente, deviniendo en una constelación de ideales de naturaleza rígida y definida.

Para Ortega -y también para García Bacca-, dicho sistema ideal y pretendidamente universal juega un papel determinante, real y estable en la propia dinámica existencial del hombre. Sin embargo, en ningún caso debe ser tenido como el único sistema racional y, menos aún, de carácter universal e inamovible. Tanto para Ortega, así como para García Bacca, el hombre posee otros sistemas de razones -vital, histórica- por las que puede -y nos atrevemos a interpretar que debe optar- de modo prioritario. A juicio de ambos autores, una existencia regida en su totalidad por la razón pura deviene, necesariamente, en asfixia y, en cualquier caso, la razón pura no es el tipo de razón inmediata a través de la cual, el hombre se maneja e interpreta su existencia en el mundo. Es muy posible que sea en este punto de la argumentación ontológica donde García Bacca encuentra la inspiración para suponer que el nuevo sistema de ideales empleados por la razón pura es, en definitiva, producto de la necesidad, la invención y la creación de un hombre utópicamente racional, y no algo fruto de una supuesta lista de categorías objetivas, apriorísticas y universales del hombre a través de las cuales, capta, piensa y racionaliza el mundo que le rodea.

Si esto es así, la razón vital puede ser interpretada como el catalizador ontológico de la autoconciencia. Es decir, la razón vital es la que hace posible que el ente se comprenda a sí mismo como parte del mundo y de su propia condición de arrojado y circunstanciado en medio del momento histórico y vital que habita. Esto es así, porque para Ortega y García Bacca la razón vital atiende a lo más inmediato, a saber, la propia existencia circunstanciada del ente en medio del mundo. Por el contrario, la razón pura, a través de su fe inquebrantable en la verdad y universalidad de lo captado por ella a través de un listado de supuestas categorías apriorísticas. En definitiva, la razón pura opta por otro sistema de verdades a través de los cuales, genera un andamiaje ontológico que emplea para abrirse ante la apariencia del mundo entendidas como cosas en sí mismas y como fenómenos desde el prisma de las categorías a priori, y no de lo más inmediato. 
Sospechamos, pues, que aún no asumiendo la totalidad del sistema ontológico-epistemológico propuesto por Ortega, si sirvió como fuente de inspiración a García Bacca para desarrollar, posteriormente, las bases de una propuesta ontológica y antropológica basada en el hecho de la circunstanciación del hombre en el mundo de cosas. ${ }^{18}$ A nuestro juicio, también contribuyó de modo crucial a desarrollar la tesis de que el hombre debe optar, escoger y priorizar permanentemente entre un sistema ideal de razones, u otro sistema de naturaleza histórica o vital.

Como se ha comentado anteriormente, a nuestro parecer es precisamente en este punto de la argumentación -finales de los años 30 y principios de los 40-, donde García Bacca coloca la primera piedra de su futuro sistema metafísico. Nos referimos, como no, al hecho de que ante la asfixia existencial que puede llegar a producir la razón pura, la razón vital debe actuar como la encargada de proporcionar al hombre el empujón necesario para ponerse $-\mathrm{y}$ nunca mejor dicho-, manos a la obra en el proceso de creación e invención de sí mismo pero, también, del mundo que habita.

\subsection{PASAdO, PRESENTE Y FUTURO EN GARCÍA BACCA}

A nuestro parecer, el punto más importante en relación con todo lo expuestos hasta el momento sea, tal vez, el sismo 9 que García Bacca dedica a Ortega en su obra Nueve grandes filósofos, y que lleva por título: Un caso de ser sin esencia. ${ }^{19}$ Tal vez lo sea precisamente porque en él, García Bacca trata como tema central el proyecto ontológico Orteguiano. Dicho proyecto ontológico tiene que ver, a juicio de García Bacca, con algunos principios fundamentales que aquí exponemos a través de diferentes argumentos y puntos explicativos.

\footnotetext{
${ }^{18}$ Como se ha comentado, pensamos que la idea de circunstancia orteguiana basada en un acceso a la propia conciencia del hombre a trabes del reconocimiento de nuestra propia razón vital es, en este sentido, el pie de apoyo necesario que el naciente proyecto metafísico garcibacquiano necesitaba. No es que García Bacca sea fiel al sistema orteguiano, pero sí es fundamental para su posterior salto al existencialismo heideggeriano que también criticara y podrá en cuestión. El sistema garcibacquiano y forma de desarrollar sus propia filosofía siempre responde del mismo modo, a saber, un acercamiento crítico-comprensivo para, posteriormente, absorber como propio algunas cuestiones atómicas que luego combinará con ideas e intuiciones de su propia cosecha. En este caso, la idea de la circunstancia o el estado de circunstanciaciado es algo que García Bacca absorbe, como estamos viendo, de su iniciática andadura metafísica por la obra de Ortega.

${ }^{19}$ Cfr. GARCíA BACCA (1990).
} 
Veamos, pues, cuáles y qué dicen dichos argumentos.

a) En primer lugar, García Bacca se refiere a la diferencia que existe entre realidad y posibilidad. Para García Bacca, el hombre entendido como ente circunstanciado en el mundo es, por definición, un hombre repleto y abierto a un universo inconmensurable de posibilidades reales. Que sea posibilidades o que disponga de ellas no lo exime, en cualquier caso, de ser en cada momento lo sido y siendo en un momento presente, esto es, lo real.

b) En segundo lugar, la imposibilidad por parte del hombre de separarse de $s u$ bistoria. La historia adquiere en la ontología Orteguiana -también en la de García Bacca-, un papel y valor clave. La historia es, de algún modo, la radical esencialidad del hombre. Lo es porque para Ortega, la historia es sinónimo de $V i d a$, de creación e invención, de la necesidad de responsabilizarse de su propia existencia en el mundo y de las circunstancias que lo determinan y definen como hombre. La historia constituye el valor definitorio de las posibilidades consumadas en actos de hecho reales. Es decir, hacen del ente lo que es en cada instante. Pero aquí, en este punto, es donde deben conjugarse los presupuestos a) y b) en un tercera idea que los aglutine argumentativamente.

c) En tercer lugar, el hecho de que el hombre sea lo sido y lo siendo -pasado y presente-, no erradica ni minimiza el valor futuro del seré. No lo hace, precisamente, porque el ente entendido como posibilidad hace que la dimensión del futuro se revalorice hasta tal punto, que libera al ente de la determinación, universalización o constitución ontológica del principio de identidad que, bajo el sustento de la razón pura es capaz de asfixiarlo existencialmente hablando. En definitiva: el hombre puede y debe inventar, crear y generar -en tanto que ente creativo repleto de posibilidades-, su futuro ser a través del empoderamiento que es capaz de proporcionar la razón histórica y vital.

Lo verdaderamente importante en este punto es, sin duda alguna, reconocer la profunda y radical influencia que ejerció Ortega sobre el inicio de la propuesta metafísica garcibacquiana.

La importancia del pasado y de la historia como esencia del hombre es clave en este punto de desarrollo metafísico garcibacquiano porque, si esencia significa o apunta al ser del ente, entonces la historia -su estar siendo lo sido en un sentido profundamente heideggeriano-, adquiere el papel clave en el asunto de la ontología garcibacquiana tal y como trataremos de demostrar. 
Para García Bacca -al menos durante los primeros años de la década de los 40 del pasado siglo-, el pasado y la historia, es decir, el sido y siendo a propósito de lo ya sido está, indiscutiblemente, constituyendo el ser presente del ente y, de alguna manera, el ser futuro. Pero para que el valor de la dialéctica adquiera poder e importancia desde un punto de vista práctico en la propuesta metafísica garcibacquiana, es preciso que al sistema ontológico de la historia interpretado como esencia de la vida se le incruste y añada el principio de las posibilidades existenciales, o lo que es lo mismo, que se libere al hombre del determinismo existencial de la pura esencialidad determinante y fijista característico de la razón pura.

En opinión de García Bacca, para que la dialéctica pueda ejercer de modo real su poder sobre la existencia humana es vital que el hombre se autorreconozca como un ente con la capacidad creadora e inventora de novedades. Es decir, que se cuente con el hecho irrefutable de que el hombre puede generar, inventar y crear las posibilidades encargadas de trocar su propia vida e historia en presente y pasado real contribuyendo, de ese modo, al sistema dialéctico-histórico que conforma el principio ontológico de Ortega y, en gran medida, del propio García Bacca. El filósofo español resume y cierra su lección dedicada a Ortega del siguiente modo:

"Para Aristóteles, como para toda la filosofía griega, escolástica y aun moderna - exceptuando tal vez a Bergson, Ortega, Heidegger y Whitehead-el modo metafísico de real está vinculado al presente o a un pasado que ha pasado por presente y en lo que sea aún presente; el futuro es un modo de ser menor que el presente, para todas las filosofías dichas y, por ser tal, no entra ni en la constitución del ser ni en la formulación de los primeros principios del ser. Empero si negamos que el futuro sea simplemente futuro en sentido clásico, si vinculamos futuro con porvenir, es decir: con creación, con invención, con libertad, con invención de posibilidades, en el principio primero que enuncie proposicionalmente la constitución de tal tipo de ser habrá que decir:

"es perfectamente posible que una cosa será tal $<y>20$ cual con simultánea posibilidad real, sólo que tendrá que ser tal $<_{\mathrm{O}}>$ cual cuando pase

\footnotetext{
${ }^{20}$ García Bacca emplea a lo largo de sus obras el símbolo [<> $>$ para destacar y resaltar algunos conceptos dentro de frases que así mismo resalta en cursiva. Nosotros las incluimos en el presente trabajo tal y como él lo hacía, para respetar al máximo sus destacados. Por esa razón incluimos las cursivas y sus destacados con el símbolo en cuestión. También respetamos en el presente trabajo la división de las citas en párrafos tal y como el filósofo español las publicara como es el caso de la presente cita.
} 
a ser efectivamente real, y en tal caso sólo podrá ser tal $<_{\mathrm{O}}>$ cual en el mismo momento presente y en el mismo aspecto.

O más brevemente, respecto de la Vida vale: puede ser tal $\langle y\rangle$ cual; es sólo tal $<_{0}>$ cual. Parecidamente, el principio de identidad hay que restringirlo al dominio de lo real existente y no puede aplicarse al dominio de lo posible antonomásticamente interpretado como posible con porvenir, como posible con libertad de invención. La ontología del hombre no es posible sino como historia y en la medida que el hombre tiene o se va haciendo con su historia". (GARCÍA BACCA 1990a, pp. 403-404). ${ }^{21}$

Sin perder el hilo de nuestra argumentación principal -la influencia de Ortega sobre García Bacca-, y tratando de revitalizar la argumentación de lo expuesto hasta el momento, nos centramos a continuación en otra de las obra de García Bacca de crucial importancia para el tema que aquí nos ocupa. En Introducción al filosofar, García Bacca expone de modo práctico ${ }^{22}$ algunas categorías tales como las de Vida, verdad, amor o desvergüenza que, de algún modo, esconden con mayor o menor descaro, una influencia y origen orteguiano.

4. INTRODUCCIÓN AL FILOSOFAR . LA IMPORTANCIA DE LA VIDA EN GARCÍA BACCA

El texto de García Bacca en el que vamos a centrar ahora nuestra atención es su obra Introducción al filosofar. ${ }^{23} \mathrm{~A}$ nuestro parecer, resultar interesante prestar atención a la Advertencia que el Dr. Eugenio Pucciarelli presenta a modo de prólogo en la obra de García Bacca Introducción al filosofar. ${ }^{24}$

Sospechamos que dicha introducción está lógicamente escrita con posterioridad a los textos que componen la obra del García Bacca. De esta advertencia de Pucciarelli destacamos lo siguiente: "Sostiene que los sistemas filosóficos dependen directamente de la vida que los engendra y responden a las exigencias que imponen las épocas históricas” (GARCíA BACCA 1939, p. 8).

${ }^{21}$ Para el concepto de Vida o de Vivir en Ortega y Gasset véase ORTEGA Y GASSET (2010). Véase también ORTEGA Y GASSET (1968).

${ }^{22}$ No a modo de lección monográfica como lo expuesto hasta el momento.

23 GARCÍA BACCA (1939).

${ }^{24}$ Eugenio Pucciarelli fue consejero de la UNT y, al mismo tiempo, vocal del la Facultad de Filosofía y Letras. El Dr. Eugenio Pucciarelli escribe la introducción a la obra de García Bacca Introducción al filosofar. Cfr. Pucciarelli, (1995, pp. 189-265). 
Y también dice Pucciarelli seguidamente: "Siempre es la vida la que otorga sentido a las ideas" (Ibíd., p. 9) .

A nuestro parecer, la afirmación que mejor refleja la objetiva e innegable relación existente entre el pensamiento garcibacquiano con el orteguiano sostenida por el propio Pucciarelli es cuando afirma lo siguiente: "Podríamos caracterizar su posición como un vitalismo historicista, atenuado con el adjetivo el matiz naturalista que suele arrastrar todavía la palabra vitalismo" (Ibíd., p. 9).

Nosotros pensamos que Pucciarelli en su advertencia en Introducción al filosofar, relaciona directamente la propuesta filosófica garcibacquiana expuesta en dicha obra, con la noción de vitalismo orteguiano. Es decir, con la idea de una filosofía que se forja en estrecha relación con la vida del autor, esto es, desde el contexto vital y circunstancial.

Por lo que a nosotros respecta, pensamos que lo verdaderamente interesante de Introducción al filosofar es, a todas luces, el esfuerzo que García Bacca realiza para tratar de llevar a la praxis los supuestos históricohermenéuticos que, hasta la fecha, habían constituido generalmente un principio teórico únicamente de estudio. Es decir, García Bacca trata de llevar los principios del ratio-vitalismo orteguiano a un nivel práctico de desarrollo y análisis historiográfico y metahistórico. Un esfuerzo práctico para tratar de objetivar los mecanismos necesarios a través de los cuales, el hombre es capaz de desarrollar y adquirir el estatus ontológico de persona.

\subsection{LOS DIFERENTES ESTADOS ONTOLÓGICOS DEL HOMBRE SEGÚN GARCÍA BACCA Y LA IMPORTANCIA DEL AMOR}

Un tema transversal a lo largo de toda la obra de García Bacca y que ocupa un puesto central en Introducción al filosofar es, sin duda alguna, la cuestión que trata los diferentes estados ontológicos del hombre: ${ }^{25}$

\footnotetext{
${ }^{25}$ García Bacca ha establecido a lo largo de su obra una especie de catálogo de estados ontológicos en los que puede encontrarse el hombre dentro de una sociedad y que, como podremos comprobar, sufrirá multitud de modificaciones tanto en las definiciones de los propios conceptos, así como en el número de conceptos que componen dicha lista. Incluso el filósofo español llegará a cambiar el nombre empleado par algunos de los conceptos de dicha lista no definitiva ni cerrada en ningún momento de su obra. Sea como fuere, esta que aquí presentamos compuesta por 5 conceptos es, hasta donde el autor del presente trabajo tiene constancia, la primera que el filósofo español publica. No cabe duda de que esta idea de generar distinciones -al menos en su origen-, está fuertemente influenciada por al distinción
} 


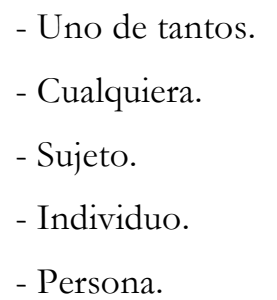

Sea anticipado y advertido el hecho de que la evolución histórica que lleva al hombre al estado aristocrático de persona según el proyecto filosófico garcibacquiano está, como podría imaginarse, supeditado a una evolución histórica de los propios estados del hombre. Evolución que viene atravesada por una serie de cambios en los principios de racionalidad -pura, histórica y vital- que, como principal resultado, abrirán al hombre a la autoconciencia de sí como persona; o lo que es lo mismo, como un ente que despliega sus posibilidades existenciales.

En este sentido, creemos que puede resultar interesante atender cómo y de qué manera García Bacca realiza todo un repaso histórico-filosófico en Introducción al filosofar que se inicia en la antigua Grecia, y que concluye en el hombre contemporáneo, pasando por el Renacimiento. Un repaso basado y centrado en la figura del filósofo y de los diferentes estados de la noción de Verdad que la han sustentado.

Ya en el prólogo de Introducción al filosofar, García Bacca centra su atención en la figura del filósofo y su relación con el concepto de amor, así como en la evolución histórico-ontológica de dicha relación. Para García Bacca, la filosofía de hoy día está íntimamente relacionada con una tríada de conceptos históricamente divinizados:

$$
\begin{aligned}
& \text { - La Verdad, } \\
& \text { - La Vergüenza } \\
& \text { - El Amor (Alétheia, Aidós, Eros). }
\end{aligned}
$$

Dice García Bacca al respecto: "El amor es el ímpetu unificador que forcejea por fusionar los seres sin conseguir identificarlos" (GARCía BACCA 1939, p. 13).

orteguiana entre personas, gente y muchedumbre que podemos encontrar en ORTEGA Y GASSET (2006). 
Si esto es así, entonces, el Eros o amor es interpretado por García Bacca como el corazón de cada ser. Es el órgano vital del hombre que proporciona el impulso y la potencia vital. Por esa razón, García Bacca afirma inmediatamente después: "Se emparenta, por tanto, histórica y vitalmente Eros con filia, dynamis y nérgueia (Amor, potencia y acto)" (Ibíd., p. 13).

Podríamos afirmar pues, que, a raíz de las palabras de García Bacca, el filósofo español relaciona e interpreta el amor como Eros, es decir, aquello que tiene que ver con la potencia propia de cada hombre para poder acceder a la verdad en estado de ocultamiento. De otro modo, para García Bacca el amor del filósofo debe interpretarse como la potencia y estado del hombre que hace posible el desocultamiento ${ }^{26}$ de la verdad -sea lo que sea la verdad-.

A nuestro juicio, García Bacca trata de exponer a lo largo de Introducción al filosofar, el hecho de que el filósofo históricamente no ha sostenido en sí ni la misma forma, ni la misma posibilidad de desarrollo existencial. El filósofo $-\mathrm{y}$ sus posibilidades mismas-, han estado muy determinadas por el grado de desarrollo y adquisición del estado mismo de persona; incluso de la noción misma de amor y verdad. Dice García Bacca en un momento dado del texto: "El hombre no se atrevió a ser esa cosa espantablemente audaz y sublime que es ser filósofo, mirar cara a cara lo que las cosas son, así se trate del tremendo ser que llamamos Dios: des-cararse y descarar a las cosas" (GARCíA BACCA 1939, p. 16).

\footnotetext{
${ }^{26}$ No podemos pasar por alto la gran estima que el propio García Bacca le procesó durante toda su vida a Platón. Tanto es así, que en su obra Confesiones Autobiografía intima y exterior, que el autor escribe a su 80 años de edad, dedicase estas sentidas palabras al filósofo heleno "En el año 1970 quedé jubilado. Toda jubilación es, en cierta manera y grado, ocasión propia, y aun deber, de hacer examen de conciencia y balance ¿a quién debo más? Y pagar en su cuantía y mérito. Sin duda alguna, a quien debo más es a Platón. Manera de pagarle: traducir sus Obras completas" (GARCÍA BACCA 2000c, p. 97). Y así lo hizo, García Bacca tradujo todas y cada una de las obras de Platón. El hecho que nos interesa en este punto es poner de manifiesto la importancia trascendental que supuso la obra del filósofo heleno y que, en este caso se nos hace translucida en el uso de algunos conceptos platónicos para su propio provecho, así como la multitud de guiños y pequeñas referencias permanentes que García Bacca va incluyendo sin problemas en el cuerpo de su argumentación y desarrollo metafísico. Para muestra, el uso del término desocultamiento o desvelamiento claramente alusivo a Platón y su mito de la caverna, o las referencias al Eros, la filia, el amor y otros conceptos propios de la filosofía platónica. En lo sucesivo del presente artículo se podrá advertir más de uno de esos guiños a los que aquí nos referimos.
} 
Según interpreta García Bacca, el hombre, por temor o vergüenza, contribuye a que las cosas del mundo permanecen en estado de oculto. Sólo el amor por la verdad logra instituir el cuerpo de la actividad vital que significa ser filósofo. Pero, aun más: "A cada tipo de amor corresponde una manera propia de descubrir las cosas y de considerarlas como encubiertas" (Ibíd., p. 16).

Haciendo apología del vitalismo que sustenta este texto, García Bacca suscribirá su amor por la vida. Para García Bacca, la vida late y fluye con tal fuerza, que es capaz de insertar dinamismo a los sistemas filosóficos compuestos únicamente de ideas fijas y rígidas. La potencia de Eros en la propuesta metafísica inicial garcibacquiana tiene que ver, a nuestro parecer, con la potencia incrustada en el corazón de todo hombre-filósofo por insuflar movilidad, fluidez e inercia a las ideas y los sistemas filosóficos. Resulta difícil, al hilo de lo expuesto hasta el momento, negar la que, a nuestro juicio, evidencia la presencia del concepto de Vida orteguiano en los argumentos garcibacquianos de Introducción al filosofar. En este sentido, para García Bacca como para Ortega- la Vida es la encargada de sustentar la casi totalidad del planteamiento filosófico-hermenéutico-historicista del hombre-filósofo.

Creemos, pues, que el amor -al menos en este punto de la argumentación de Introducción al filosofar- pero, también en el fundamento filosófico garcibacquiano de los años 40 del pasado siglo, juega el papel principal de la propuesta ontológica. Dice García Bacca: "En la vida humana late la radical potencia de hacer del hombre un singular, un individuo, una persona y un hijo de dios" (GARCíA BACCA 1939, p. 17).

Con esta afirmación, creemos que García Bacca está exponiendo con rotunda claridad los cuatro tipos o momentos históricos por los que ha pasado el concepto de amor del hombre-filósofo: ${ }^{27}$

- Singular.

\footnotetext{
${ }^{27}$ Los listados de los diferentes conceptos en los que García Bacca presenta el desarrollo histórico del hombre en sociedad estaban sujetos a posibles cambios. El caso que presentamos a continuación no es una excepción. Dentro de la misma obra, García Bacca troca el listado inicial histórico de 5 estados, a un listado más concreto y específico de 4 que, en el caso que aquí exponemos, se refiere concretamente al concepto de amor como hilo conductor de esa evolución histórica del hombre social. Sea como fuere, es menester poner en aviso al lector que la primera de las listas dadas por García Bacca es, sin duda alguna, la que podemos considerar como la génesis de la que crecerán el resto de futuras modificaciones realizadas por el filósofo español a lo largo de su dilatada obra.
} 
- Individuo.

- Persona.

- Hijo de Dios.

Para García Bacca, estas son las cuatro posibilidades existenciales que están relacionadas, a su vez, con los cuatro niveles de la vida histórica anteriormente citados. A nuestro juicio, se desprende, pues, una afiliación estrecha por parte de García Bacca respecto al vitalismo histórico orteguiano, así como lo que, a nuestro modo de ver, constituye un sustrato evidentemente dialéctico. Para García Bacca, la vida existencial del hombre está sujeta al flujo del devenir histórico. Flujo que determina, a través de las diferentes concepciones del amor, las heterogéneas posibilidades axiológicas y existenciales del hombre.

Siguiendo el hilo de lo expuesto, es momento de analizar el tipo de talante y carácter que García Bacca atribuye al hombre-filósofo que, en un esfuerzo dialéctico por tratar de alcanzar el estado de persona, termina descubriéndose como un "desvergonzado".

\subsection{EL DESVERGONZADO Y EL VITALISMO CRÍTICO GARCIABACQUIANO}

Para García Bacca el adjetivo que mejor define el talante y carácter del hombre-filósofo enamorado de la vida y de la tarea de tener que crear e inventar su propio mundo es, sin lugar a dudas, el de Desvergonzado. Tratemos de averiguar por qué.

En opinión de García Bacca el hombre-filósofo vitalista termina descubriéndose a sí mismo como un desvergonzado. Para García Bacca, el hombre-filósofo descubre su talante como descarado, en el mismo instante en el que intenta descarar las cosas que se le presenta ante sus ojos y manos. Como veremos, para alcanzar este estadio histórico de filósofo-hombre-persona al que aspira García Bacca durante los años 40 del pasado siglo, ha sido necesario un proceso histórico-dialéctico de las posibilidades histórico-existenciales del hombre. Posibilidades que han estado marcadas y determinadas por las diferentes concepciones históricas del amor, así como por los papeles que en las diferentes épocas históricas han jugado la verdad y la vergüenza.

El propio filósofo español sintetiza las ideas sobre el tipo de amor y de verdad que él, de modo desvergonzado y humilde, considera propios de la actitud filosófica del hombre moderno: "Mas recuerde el lector que la $<$ verdad $>$ es una cierta $<$ desvergüenza $>$, cuya acción propia es $<$ des-cararse y 
des-carar las cosas $>$ (...) ¡Des-vergüenza y des-caro! ¡Virtudes propias del filósofo amante de la <verdad>!" (GARCía BACCA 1939, p. 1939)"

Es decir, para García Bacca la autoconciencia del hombre en su estado o fase de conciencia de sí como persona -como filósofo desvergonzado que atenta contra lo velado-, no es algo que se produzca de un día para otro en el propio devenir histórico. Dicho devenir dialéctico es producto, en opinión de García Bacca, de un movimiento constante tanto de los estados ontológicos en los que se encuentra el hombre, así como el tipo de razón que en ese momento sustenta la hegemonía interpretativa del mundo. Dice García Bacca: "Aun el hombre no ha nacido con la conciencia plena de su individualidad; y, por tanto, con la potencia de aislarse, de hacerse solitario. Esta conciencia de individualidad y potencia de soledad son fenómenos históricos tardíos, conquistas del renacimiento" (Ibíd., p. 48).

Es decir, en opinión de García Bacca, la idea que hoy se tiene del individuo entendido como sujeto aislado y definido dentro de los límites de su personalidad es, a nuestro entender, el producto de una evolución históricodialéctica de diferentes modos de vida existencial.

Pero, a nuestro juicio, aún existe algo más significativo en este sentido si cabe, a saber, el hecho de que para García Bacca, el tipo de lógica que atraviesa y guía, es decir, que determina cada cambio histórico en sí mismo independientemente de que exista tal y como creía Ortega, una racionalidad relativamente calculable o probabilística-, a pesar de todo ello, decíamos, para García Bacca la lógica de cambio y transformación es de naturaleza espontánea. Dice García Bacca al respecto: "El nacimiento de las cosas y del hombre son inseparables. Sin hombre que se individua a sí mismo por desarrollo espontáneo de la vida no habría cosas" (Ibíd., p. 53).

De nuevo se observa en las palabras de García Bacca la que, a nuestro entender, se revela como la posibilidad evolutiva-dialéctica de la noción de vida. Ahora bien, a nuestro parecer, lo más destacable de las palabras de García Bacca sea, tal vez, la idea de espontaneidad intrínseca al proceso históricodialéctico de la propia evolución del la noción de vida. Al parecer, el cambio de perspectiva o de tendencia ontológica introducida por García Bacca respecto a las nociones orteguianas no responde, a nuestro entender, a un pre-programa lógico y rígido. Más bien, dicho cambio se produce por natural espontaneidad.

Si esto es así, a la filosofía únicamente le queda, en opinión de García Bacca, la posibilidad real de rastrear los fenómenos acaecidos en el cambio contante de las perspectivas ontológicas desde un punto de vista histórico. 
Nosotros creemos que García Bacca, al menos en esta fase o estado de su propuesta metafísica, está inmerso casi por completo en una revisión crítica sobre los principios que sustentan el ratio vitalismo orteguiano. Tanto, que no resulta sorprendente expresiones por parte de García Bacca del tipo: "Resulta ya una candidez suponer que la filosofía y las ciencias pueden construirse perfectamente en un plano ideal puro sin que la estructura del tipo de vida influya en la de la ciencia” (Ibíd., p. 53).

Afirmaciones de este tipo por parte de García Bacca ponen de manifiesto, a nuestro juicio, la tesis ontológica principal que atraviesa y sustenta la propuesta metafísica de García Bacca durante los años 40 del pasado siglo. Dicho principio sobre el que se sustenta el inicial argumentario metafísico garcibacquiano puede ser resumido por nosotros del siguiente modo: los tipos de vida determinan de raíz los tipos de ciencia, filosofía, metafísica, antropología, etc., El poder del vitalismo que acontece en formas indeterminadas a priori condicionan el futuro proceder de las diversas áreas de la existencia humana.

Bajo el supuesto ratio-vitalista orteguiano, García Bacca desarrollará en estos primeros años de andadura metafísica, la hipótesis ontológica de que todo sistema científico, político, filosófico, religioso, social, etc., queda atravesado y sostenido por la lógica espontánea de la vida misma. El propio

García Bacca nos recuerda en Introducción al filosofar. "La variable independiente en la evolución histórica de las ciencias es el proceso y progreso interno de la vida del hombre, comenzando por la formación espontánea de su individualidad"( GARCíA BACCA 1939, p. 51).

A nuestro parecer, estas palabras de García Bacca expresan con absoluta rotundidad la idea de que las ciencias crecen y se desarrollan directamente a partir de la evolución histórica. Evolución que, por primera vez en toda la obra de García Bacca, el filósofo español catalogada como progreso. Nosotros creemos, pues, que García Bacca reitera de modo velado en estas palabras, la idea de que el progreso interno, dialéctico y vital que nos encamina hacia la individualidad es, esencialmente, de carácter espontáneo.

Nos preguntamos nosotros ahora a propósito de las palabras de García Bacca y su idea de progreso: ¿La idea de progreso tiene que ver con el avance lineal y continuo tal y como ocurre en un proceso dialéctico ideal? ¿La espontaneidad del progresar existencial del hombre está reñido con un 
supuesto encaminarse programático y lógico hacia la conquista de la madurez existencial del hombre, es decir, hacia la consecución de la personalidad? ${ }^{28}$

\subsection{LA “FAENA VITAL” GARCIABACQUIANA DE SER "PERSONA”}

El apartado E) de Introducción al filosofar titulado Nacimiento de la unidad individual finita es crucial para la compresión de una cuestión crucial en la propuesta metafísica garcibacquiana. En dicho apartado, García Bacca expone por primera vez la trascendental importancia que adquiere el desarrollo del estado ontológico de persona para su propio proyecto metafísico.

Dice García Bacca al respecto: "Ser individuo es, en rigor, hacerse individuo, madurar dentro de la especie ya madura, la individualidad. El individuo y su individuación no son cosas ni propiedades de cosas (algo hecho) sino faena vital, función del tiempo histórico" (GARCíA BACCA 1939, p. 69).

A nuestro parecer, en estas palabras de García Bacca se hace más que evidente la presencia de la noción histórico-dialéctica orteguiana de la constitución de ser persona. Lo novedoso en las palabras garcibacquianas respecto al argumento orteguiano es, a nuestro modo de entender, la importancia que adquiere la idea de faena vital en la propuesta garcibacquiana puesto que, en su caso, el hecho de constituirse ontológicamente como persona no acontece inmediatamente; ni tampoco le acontece a un sujeto sin más.

Es discutible si esta protodefinición garcibacquiana de individuo es satisfactoria o no. Incluso estaríamos de acuerdo con opiniones que defendieran la poca claridad respecto a la definición de individuo dada por García Bacca en Introducción al filosofar. Sea como fuere, el término "individuo" empleado por García Bacca, -al menos en esta fase inicial de su propuesta metafísica- debe servirnos únicamente como acicate hacia un desvelamiento

\footnotetext{
${ }^{28}$ Dejemos, por el momento, estas cuestiones abiertas. Baste, para el tema que nos ocupa, la exposición de lo que, en estos primeros años de influencia orteguiana, se autoevidencia como una especie de semi idealismo dialéctico-vitalista que, a nuestro juicio, es consecuencia de las esperanzas puestas en las supuestas leyes que regularían la evolución existencial desde el uno de tantísimos o cualquiera, hasta el estadio de persona. Esta fe en ciertas reglas, estadios y principios en la evolución dialéctica existencial denota, cuanto menos, un cierto principio de idealidad. Idealidad que, en cierto sentido, irá reformulando y ajustando hasta alcanzar en los últimos escritos de García Bacca, un grado de materialismo dialéctico. Sin embargo, los fundamentos y proyectos metafísicos en estos primeros años, aun dependía mucho de los supuestos orteguianos.
} 
progresivo sobre dicho concepto a lo largo de sus obras. En cierto sentido, lo único que podemos extraer como inicial principio definitorio de la categoría de individuo garcibacquiano en su estado inicial, es que se trata de algo sujeto a un proceso de creación histórico y social. Es decir, algo no dado ni estable en ningún caso y sujeto a un proceso dialéctico de mutación.

Si esto es así, es decir, si el concepto de individuo garcibacquiano está sujeto a mutaciones de carácter dialéctico, entonces el ser-individuo tiene que ver con la tarea y la responsabilidad vital de tener que hacerse-crearse uno a sí mismo como individuo. No podemos escapar pues, a la tarea ontológica de constituirnos como sujetos. Y ello se debe, muy probablemente, a que el flujo histórico-dialéctico sobre el que se sustenta el desarrollo histórico-social nos empuja de modo inevitable a ello. El aparecer de la individualidad como tarea ontológica es algo que, como comentamos anteriormente, acontece espontáneamente, es decir, que no parece existir contradicción entre la espontaneidad del encaminarse hacia la individualidad existencial por un lado, y la faena de tener que hacerse uno a sí mismo como individuo.

Dicho lo mismo, pero en palabras del propio García Bacca: "Hombre se define como melodía entitativa, no como acorde solitario. En el primer compás de la vida humana el hombre ha sido especie; en el segundo, la especie se ha superado y completado en su sentido vital en la individualidad; en el tercero, el ímpetu vital, desbordado ambos moldes, se supera y es absorbido por la nueva forma vital de la personalidad: así por sucesivas superaciones y absorciones" (Ibíd., p. 69).

Esta es una de las citas donde a nuestro modo de entender, García Bacca expresa con mayor claridad la idea del esquema dialéctico al que estamos constantemente refiriéndonos. Esquema que, como anteriormente se afirmaba, tal vez padezca de cierto grado de idealismo. A pesar de que la evolución vital propuesta por García Bacca queda sostenida -en estos primeros años de propuesta metafísica-, por una difusa noción de espontaneidad. A pesar de ello, decíamos, el proceso dialéctico-evolutivo existencial queda sostenido por ciertas reglas y leyes de naturaleza fija y determinada.

$\mathrm{Y}$ es que, en cierto sentido, el relativo idealismo dialéctico que atraviesa estos primeros años de desarrollo metafísico garcibacquiano, hace que los supuestos filosóficos propuestos por el filósofo español no puedan 
desprenderse totalmente de un cierto aroma aristocrático ${ }^{29}$ que siempre ha sostenido la filosofía de Ortega a juicio del propio García Bacca. Para muestra, el siguiente fragmento:

"Yo me rebelo contra tal esclavitud fatal al plebeyísimo metafísico: y digo que la vida humana -que es algo anterior, superior y originario frente a todo aspecto hecho, llámese ser, cosa, substancia...- puede poseer bajo forma plebeya, unívoca, todo eso e inclusive analizar en sentido muy real la diferencia

29 A partir del conocimiento de la obra de Machado -final de los años 50-, García Bacca rechazará el "elitismo" filosófico o sentido "aristocrático" en el que, a su juicio, su propio discurso filosófico había incurrido especialmente durante la $3^{\circ}$ etapa de su pensamiento y que, en el presente artículo, estamos tratando de modo monográfico. Si bien el asunto del "elitismo" filosófico en la obra de García Bacca no es, ni mucho menos el tema central de nuestro trabajo, si consideramos que debe ser tenido en cuenta para futuros trabajos dado que, a nuestro modo de entender, es clave para comprender la transición entre la $3^{\circ}$ etapa existencialista que aquí tratamos, y la $4^{\circ}$ de las etapas garcibacquianas. Si bien el tema del abandono por parte de García Bacca supera en mucho al tema que aquí tratamos, si conviene señalar algunos aspectos fundamentales que bien pudieran servir al lector para ubicar argumentativamente dicho asunto. La superación del elitismo por parte de García Bacca tiene que ver, grosso modo, con el cambio de paradigma ontológico que el propio filósofo español experimentará al abandonar a principios de los años 60 -por superación y absorción- tanto la forma, así como el propio contenido de las disposiciones argumentativas de Ortega y Gasset. Forma y contendido argumentativo aristocrático -juzgado como elitista posteriormente- que García Bacca defendió durante los primeros años de su tercera etapa filosófica, y que en el presente trabajos estamos analizando. El elitismo filosófico del que García Bacca consideraba que había sido preso durante los años 40 se puede concentrar en la siguiente tesis: durante la etapa orteguiana, García Bacca defendía que los temas de filosofia debia ser tratados, estudiados y pensados principalmente por filósofos, los cuales, debian ser devueltos al pueblo o masa con la intención de instruir y corregir los defectos de la propia sociedad. Aún siendo posible que esta opinión garcibacquiana supusiera un cierto exceso de interpretación por su parte, lo cierto es que el redescrubrimiento por parte de García Bacca de la obra de Machado genera un nuevo paradigma social-filosófico en el pensador español que, inevitablemente, lo empuja a pensar que los temas a los que debe atender un filósofo deben ser, por imperativo social, todos aquellos que repercuten y afectan al conjunto de las sociedades. Es decir, la sociedad establece la hoja de ruta para los filósofos y no a la inversa. Éstos deben sondear la sociedad -al pueblo- con la intención de hacer resaltar los problemas y preocupaciones principales que, debido a dicha responsabilidad social que determina en su esencia, debe atender y pensar. En definitiva, el propio García Bacca considera que gran parte de su producción filosófica anterior al redescubrimiento de Machado $-1^{\circ}, 2^{\circ}$ y $3^{\circ}$ etapa respectivamente- llevaba asociada, inevitablemente, cierto tufo elitista por no haber centrado su atención en los principales problemas sociales del momento. Para mayor información respecto al abandono por parte de García Bacca del tono elitista y el redescubrimiento de la poesía de Machado consultar mi trabajo GIMENO (2015).

Análisis. Revista de Investigación filosófica, Vol. 2, n. ${ }^{\circ} 1$ (2015): 63-107 
específica; mas puede también, viviendo íntegra, absolutamente, abiertamente la vida humana, vencer el plebeyísimo metafísico - la univocidad- y hacerse original, única, en cuanto individuo y en cuanto persona y en cuanto vida arrastrando en esta ascensión y faena de aristocratización a todos los aspectos metafísicos, aun los llamados análogos. Aristocracia y plebeyísimo metafísicos no son, pues, estados que se posean por nacimiento y no puedan perderse ni aumentarse; son conquistas de la vida humana, trofeos de caballeros cuyo lema sea vivir, vivir plenamente, gozosamente, valientemente la vida humana" (GARCÍA BACCA 1939, p. 70).

Es cierto que hacia el final de las palabras de García Bacca se especifica que tanto la aristocracia, así como el plebeyísmo metafísico, no son estados determinados y prefijados en las personas por nacimientos. Son estados que se conquistan o pierden. Se ganan o se pierden dependiendo de si el hombre actúa según el lema de aquél que, valiente, vive plenamente la vida. No sabemos qué o en qué cosiste "vivir plenamente la vida"; ni qué quiere señalar García Bacca con lo de "vivir gozosamente la vida". Tampoco tenemos claro qué entiende por "ser un valiente", como no se refiera al hecho de tener que hacerse cargo y ser responsables de nuestro propio existir como sujetos inmersos en el flujo dialéctico-existencial.

Sea como fuere, ser valiente o vivir gozosamente la vida, pensamos que, para García Bacca, implica lo siguiente: salir progresiva y espontáneamente del estado inmaduro de individualidad. Tal vez con el fin de hacerse uno cargo de la espontánea e imparable posibilidad propia de todo hombre. Posibilidad encaminada hacia la consecución de su propia autonomía como hombre, es decir, como individuo.

En este sentido, pues, el concepto de aristocracia a la que apunta García Bacca queda asociado, a nuestro modo de entender, con la imagen de aquél hombre que, valiente, decide hacerse cargo de su finitud. Es decir, de su ilimitación y, esencialmente, de la tarea vital de vivirse a sí mismo en un constante tener-que-hacerse.

Y en una especie de conclusión no definitiva al respecto, García Bacca concluye del siguiente modo: "Llegará un tiempo en que el hombre se canse y se rebele contra la sujeción impuesta por el oficio ontológico de ser altavoz metafísico de las cosas: será la razón histórica del nacimiento y desarrollo de la individualidad" (GARCÍA BACCA 1939, p. 72).

Es decir, para García Bacca el cansancio y agotamiento de una forma de vida o estado existencial es razón suficiente y necesaria para dar paso al 
proceso dialéctico de individuación. Dicho principio de necesidad y legalidad en los cambios y transformaciones dialécticas siguen sin ser incompatibles con la idea de espontaneidad propuesta por García Bacca. De otro modo, para García Bacca el cansancio de un estado de vida no tiene por qué determinar a priori el nuevo enfoque existencial-vital hacia el que, a su modo de entender, se encaminan los valientes. O mejor aún, que la espontaneidad en la que se sustenta la vida creativa, no es necesariamente incompatible con el hecho en sí de que el flujo dialéctico-existencial en constante y permanente mutación, quede determinado por ciertos supuestos y principios con los que hacer ciencia e historia. Uno puede, perfectamente, hacer metahistoria del hombre a partir de los cambios de orden y naturaleza espontánea y, a pesar de ello, poder determinar siempre a posteriori las razones que sostuvieron el cambio de paradigma existencial.

Otra cuestión es saber si, a propósito de la metahistoria propuesta por García Bacca, el hombre puede pronosticar con rigurosidad hacia dónde y qué consecuencias tendrá el sostenimiento y desarrollo de un nuevo paradigma existencial. Sea como fuere, es menester dejar esta cuestión abierta por el momento.

Y llegados a este punto, centramos nuestra atención en la noción de verdad según la desarrolla García Bacca durante los primeros años de la década de los 40 del pasado siglo.

\subsection{LA NOCIÓN INICIAL DE “VERDAD” EN GARCÍA BACCA}

Recordemos que la noción de verdad - en Ortega- se basa en la premisa del perspectivismo. Premisa que intenta salvar los escollos tanto del relativismo, así como del racionalismo. En cierta medida, García Bacca no pude desprenderse de esta idea del perspectivismo vital. Razón por la que García Bacca desarrolla durante los primeros años de la década de los 40 del pasado siglo, lo que nosotros hemos considerado una especie de readaptación crítica de dicho perspectivismo entorno a la noción de verdad orteguiana. Dicha adaptación se desarrolla, como era de esperar, siguiendo las pistas que el propio concepto de verdad ha dejado a lo largo de la historia de la humanidad. En cierto modo, creemos que con el repaso historiográfico realizado por García Bacca respecto del concepto de verdad analizado desde la antigua Grecia hasta la modernidad, pasando por el Renacimiento está, de algún modo, tratando de mostrar el sentido de la verdad como perspectivismo. Es decir, tratando de relacionar verdad y 
perspectivismo dado que, en su opinión, el concepto de verdad únicamente pude legitimarse si se asocia con el concepto del perspectivismo.

Por eso, en el epígrafe D) de Introducción al filosofar encontramos lo que, a nuestro juicio, constituye uno de los puntos fuertes de su argumentación respecto a la noción de verdad. Es posible determinar las bases de su propio pensamiento sobre lo digno de una nueva fórmula de verdad partiendo, para ello, de nociones tales como la de desvivirse. Es decir, de la verdad desprendida de las cosas, desvivida de las cosas y de la esencial necesidad de ser altavo $2^{30}{ }^{30}$

Desvivirse es, según lo entendemos nosotros, un nuevo modo de vida. Este nuevo modo o estado de vida reniega de la contemplación como método de acceso a la verdad. Por el contrario, la verdad requiere de un esfuerzo, es decir, de un trabajo activo por parte del hombre: "La verdad ontológica o trascendental sólo se comienza a presentar en la conciencia cuando la vida se

${ }^{30} \mathrm{El}$ término altavoz constituye un término clave en el desarrollo ontológico de García Bacca que merece cierta atención por nuestra parte. Atendiendo a la fórmula griega, advertimos que debido a su "estructura vital", decía en voz alta lo que silenciosamente eran las cosas. Aquí será donde, hasta ahora, García Bacca empleará por primera vez la expresión altavoz para caracterizar el sentido ontológico de la actividad metafísica del hombre antiguo. Para García Bacca, ser griego es ser altavoz del universo. Para poder entender correctamente esta expresión, deberemos hacer referencia a la relación estrecha que existente entre el lenguaje y las cosas en la época griega -para esto podríamos hacer referencia a la obra de BOTTERÓ (2004). en la que también se trata esta relación entre cosas y lenguaje. Hoy día carece de sentido la posibilidad de ser altavoz del universo esencialmente, porque el lenguaje se ha independizado, se ha desconectado del pensamiento y de las cosas. Como dice García Bacca, éste posee sus leyes internas. A propósito de esto, García Bacca expone en Introducción al filosofar, las tres etapas de lo que, según él, constituye el proceso de independencia del lenguaje. Independencia progresiva e histórica por la que el hombre ha dejado de ser altavoz. La primera etapa -la griega-, el lenguaje estaba sometido a las cosas e ideas: lenguaje en función ontológica. Segunda etapa, el lenguaje se independiza de las cosas, pero sigue sometido a las ideas: lenguaje en función lógica. La tercera etapa, el lenguaje se independiza, se desconecta de cosas e ideas: lenguaje puro.

Para el griego en su función de altavoz: palabras e ideas nacen del mismo sitio. Como altavoz, éste está conectado con el "cosmos". El antiguo griego con su lenguaje en función ontológica, puede "decir" lo que las cosas son, y lo que éstas le tienen que decir a él. García Bacca asegura que únicamente cuando el antiguo griego empieza a sentirse desconectado de las cosas, es cuando empieza a dejar de ser altavoz. Es decir, es cuando la pregunta ¿Qué es? Hace acto de presencia. Dice García Bacca sobre el concepto mismo de altavoz: "El hombre es "altavoz" entitativa. Es altavoz conectado esencialmente con el cosmos, para decir no lo que quiera, sino lo que las cosas son y tienen que decir por él” (Ibíd., p. 20).

Análisis. Revista de investigación filosófica , vol. 2, n.ำ 1 (2015): 63-107 
retira de las cosas y pretende vivirse sin desvivirse en y por las cosas" (GARCÍA BACCA 1939, pp. 90-91).

A nuestro parecer, García Bacca está tratando de asentar argumentativamente las bases de un nuevo modelo aristocrático de verdad. Para empezar, dicha verdad es fruto de un proceso histórico-dialéctico. Este nuevo modelo de verdad surgida de modo espontáneo ha cambiado la luz, el deslumbramiento y la quietud contemplativa característica de la Antigua Grecia, por una actitud activa propia de nuestro tiempo. Es decir, por una interacción directa - personal- con las cosas. Se ha pasado de la mirada del ojo, al tacto de la mano. Se ha pasado del terror a lo indefinido, a la valentía de aquél que ahora no perfila o no define disolviendo o negando la diversidad predominante. La verdad, según la entiende García Bacca, es resultado de un proceso de valentía, trabajo y esfuerzo. Es decir, para García Bacca, los valientes -los aristocráticos- viven plenamente la vida porque son sabedores de la tarea inevitable que conlleva el hecho de vivirse. Para los primeros iniciados en el desvivirse de las cosas: Sócrates, Estoicos y Escépticos, la epojé actúa como catalizador en el tránsito entre la verdad y la metafísica clásica óntica-, y la verdad y metafísica moderna -ontológica-.

Pero aún más, la verdad abandona para García Bacca radicalmente la idea de única y universal. La verdad, ahora, arrastrada por el fluir vital, ha mutado y trocado su estado de luminosidad divina sustituyéndola por una personificación del hombre por el hombre; persona por persona. De este modo, la verdad se establece como una comunidad interminable de perspectivas compartidas y coajustadas las unas con las otras.

Así sentencia García Bacca lo que, a su juicio, debe entenderse hoy día por verdad -al menos se trataría de la noción ideal de lo que debe entenderse por verdad-: "La verdad es el movimiento trascendental, si es lícito llamarlo así, que va precisamente del estado de intrasparencia al de trasparencia de lo que se es. En este proceso interviene una repetición y una unión y continuidad. La identidad no es, por tanto, sino la continuidad en el proceso de trasparencia" (GARCíA BACCA 1939, p. 96).

En las palabras de García Bacca sobre la verdad y su naturaleza de constante y perpetuo movimiento existen, a nuestro parecer, cierta reminiscencia a la noción heraclitiana respecto al cambio y la dialéctica. Consabido el gran aprecio que García procesaba a Platón, no nos cuesta creer, pues, que el filósofo español rememorase aquellas palabras que Platón dedica a Heráclito cuando dice: 
"Heráclito dice en alguna parte que todas las cosas se mueven y nada está quieto y comparando las cosas existentes con la corriente de un río dice que no te podrás sumergir dos veces en el mismo rio" (PlATÓN 402A, p. 262).

Si esto es así, creemos que existen poderosas razones para interpretar que, en el caso de García Bacca, la verdad, igual que ocurre con el concepto de vida, está sometida a un idéntico proceso dialéctico de cambio, trueque y transformación. Es más, se podría argumentar que el tipo de verdad que predomina en cada momento histórico es, en el caso de García Bacca, producto directo del tipo o estado de vida así como de la perspectiva ontológica que en cada estadio o etapa histórica sostenga existencialmente a los hombres.

Y así, de esta manera, García Bacca expone el sentido y valor profundo de la propia vida como sustento y soporte de la verdad. La vida de uno -la de cada uno de nosotros-, es concebida por García Bacca como fuente inagotable de espontáneas e imprevisibles transformaciones que proporcionan, así, sin más, las razones necesarias y suficientes para que la verdad no deje en ningún momento de trocar y cambiar. Es decir, de combinarse entre ellas generando y ampliando, transformando e inventando a cada momento el valor mismo de verdad entendida como perspectiva:

"La vida humana está por esencia en el mundo. Sólo la manera de estar en el mundo es función del tipo de vida. La vida humana, como toda vida finita, no puede funcionar en el vacío absoluto. El vivir humano es esencialmente reflexivo y transitivo de vez: es un vivirse y un desvivirse. La evolución vital consistirá en ajustar el tipo de vivir y desvivirse a uno de estos juegos de palabras: vivir desviviéndose en las cosas, vivir desviviéndose de las cosas, vivir viviendo en sí mismo las cosas, vivir viviendo de sí mismo las cosas. Pero siempre vida y cosas" (GARCÍA BACCA 1939, p. 108).

En estas palabras del filósofo español es posible rastrear y anticipar el germen de una de las influencias determinantes no sólo dentro de la $3^{\circ}$ etapa de pensamiento garcibacquiano sino, también, del resto de etapas filosóficas dentro de la dilatada trayectoria filosófica garcibacquiana. Nos referimos, pues, al filósofo alemán Martin Heidegger. ${ }^{31}$ En cualquier caso, el desvivirse no deja de ser un tipo o estado de vida para García Bacca. Lo destacable en este punto

${ }^{31}$ El tema de la influencia de Heidegger en la obra de García Bacca es complejo y extenso. Por razones de extensión, dejamos para otra ocasión este asunto. Para mayor información sobre este asunto, consultar mi trabajo GIMENO (2014, pp. 111-128). 
de la argumentación es, a nuestro modo de entender, la referencia constante por parte de García Bacca a nociones de origen orteguiano que ponen de manifiesto, una vez más, la filiación crítica garcibacquiana al ratio-vitalismo orteguiano $\mathrm{y}$, en cierto sentido, su tímida e inicial aproximación a la fenomenología heideggeriana.

\section{COLORARIO}

En este punto de la argumentación no podemos pasar por alto la diferencia establecida por García Bacca entre los términos en y de. ${ }^{32}$ Diferencia que, a nuestro juicio, concentra el sentido primero de todo lo expuesto hasta el momento. Es decir, que dicha diferencia nos sitúa en un nivel ontológico del discurso con el que el filósofo español intenta dotar de sentido a su tesis dialéctico-existencialista que, como acabamos de ver, hunde sus raíces en un sentido primigenio y profundo en los supuestos ratio-vitalistas orteguianos.

Por esa razón, qué mejor final para nuestra exposición sobre la génesis del proyecto metafísico garcibacquiano y su gestación en muchos de los principios del racio-vitalismo orteguiano, que las propias palabras de García Bacca con las que cierra su Introducción al filosofar y que, en nuestra opinión, resume las bases de su propuesta fenomenológico-historicista:

"La vida humana ha realizado, por ahora, cuatro tipos de vivir:

a. Vivir desviviéndose en las cosas.

b. Vivir desviviéndose de las cosas.

c. Vivir viviéndose en sí misma las cosas.

\footnotetext{
${ }^{32}$ No cabe duda que esta diferencia poco sutil entre el en y el de establecida por García Bacca pueda resultarnos compleja. Nosotros únicamente referiremos en el presente artículo que dicha diferencia establecida por el filósofo español trata de establecerse, a nuestro modo de entender, como un sistema de clasificación de tipo fenomenológico ante los diferentes tipos de vida desarrollados a lo largo de la historia del hombre. Tipos de vida que ha tratado de desarrollar García Bacca en Introducción al filosofar y que, en nuestra opinión, puede ser considerada como la primera obra garcibacquiana de orientación fenomenológica al más puro estilo hegeliano y primera obra de calado metafísico. Para mayores referencias sobre las distintas etapas de vida dentro de la obra Introducción al filosofar, consultar la obra (tesis doctoral) de BEORLEGUI (1986, pp. 242-259). En ella, Beorlegui afirma: "La historia del hombre y del mundo es la historia de los diferentes procesos o situaciones de relación entre la vida y las cosas, que es lo mismo que la historia del proceso de la vida como ser indeterminado, inmediato e incomplejo en su proceso circular de expandirse hacia fuera y relegarse hacia dentro" (BEORLEGUI 1986, p. 242).
} 
d. Vivir viviéndose de sí misma las cosas.

Con otras palabras: vivir como singular como individuo perfecto o imperfecto y como persona” (GARCÍA BACCA 1939, p. 164).

Es decir, García Bacca ha reagrupado en 4 estadios vital-existenciales, el sentido dialéctico de sus premisas ontológicas desarrolladas durante los primeros años de la década de los 40 y que, como hemos tratado de mostrar, hunden sus raíces en la propuesta racio-vitalista orteguiana.

Como hemos tratado de mostrar, para García Bacca el hombre debe de dirigir su desarrollo existencial hacia el estadio ontológico más elevado, es decir, hacia el estado de persona. Ser persona es, en el caso de García Bacca, la forma en la que el hombre tiene conciencia - no sabemos si plena- de sí como sujeto sustentado y atravesado por el principio de vida. Es decir, bajo la lógica que impone el desarrollo de la razón vital.

García Bacca concluye su Introducción al filosofar con las siguientes palabras: "La faena de los estudiosos de este volumen y de los primeros temas del siguiente (la vida personal, la vida religiosa, formas mixtas de vida...) podría caracterizarse, si Hegel no protesta del plagio, fenomenología de la vida, o con un emocionante término de Ortega, Salvación de la vida" (Ibíd., p. 164).

\section{CONCLUSIONES}

Para estas conclusiones, hemos optado por tratar de recopilar de modo breve y conciso las que, a nuestro modo de entender, constituyen las principales ideas desarrolladas en el presente trabajo.

Somos plenamente conscientes que tanto la temática -la influencia de Ortega sobre un periodo muy concreto dentro de la extensa obra garcibacquiana-, así como el modo en el que ha sido presentado puede llegar, en más de una ocasión, a generar cierto grado de confusión. Incluso existe la posibilidad real de generar la sensación en el lector de una posible ausencia de hilo argumentativo conductor. Por nuestra parte, únicamente nos queda tratar de justificar esas posibles confusiones o problemas producto más de la propia forma de hacer filosofía del propio García Bacca, que de una real falta de coherencia argumentativa por nuestra parte.

Es un hecho innegable que, durante la práctica totalidad de la obra de García Bacca, la ausencia de citas y referencias bibliográficas es casi absoluta. Tampoco existe, por lo general, un plan previo de trabajo argumentado por parte de García Bacca. Este conjunto de hechos objetivos producto de un 
estilo de trabajar muy personal, dificulta terriblemente a los investigadores de la obra y vida de García Bacca una aproximación a sus temas e influencias dentro de cada periodo de su obra. En el caso de Ortega y su influencia en la obra de García Bacca este problema no desaparece. La opacidad a la que nos tiene acostumbrados García Bacca no deja espacio prácticamente nunca a los investigadores en su vida y obra, para tratar de lograr una coherencia y continuidad argumentativa a la hora de exponer el análisis de sus obras. Por esa razón, en el presente trabajo se ha tratado de agrupar por temática aquellas referencias bibliográficas garcibacquianas que trataran el tema de Ortega y su filosofía. Sobre dicho conjunto de referencias bibliográficas hemos tratado de extraer aquellos argumentos principales que, si bien en muchos casos es posible que generen una cierta sensación de desapego o falta de continuidad argumentativa, en el fondo tratan de aunar en la medida de los posible una colección de argumentos expuestos por el filósofo español de modo disperso y, en la mayoría de las ocasiones, carente de continuidad argumentativa.

A pesar de todas las dificultades propias y ajenas del presente trabajo, nosotros creemos que hemos sido capaces de agrupar aquellos argumentos garcibacquianos que conforman a lo largo de unos pocos años -primeros años de la década de los cuarenta del pasado siglo-, el quicio argumentativo sobre el cual, nosotros hemos tratado de demostrar en qué claves se sostiene la influencia que el profesor Ortega ejerció sobre los primeros pasos -años $40 \mathrm{del}$ pasado siglo- de la propuesta metafísica garcibacquiana.

Por esa razón, hemos tratado de asentar de modo breve y conciso en qué consisten algunos elementos argumentativos significativos de la novedosa propuesta raciovitalista orteguiana. Para ello hemos descrito muy someramente en qué cosiste la hermenéutica historicista a la que García Bacca se agregará de modo significativo durante este periodo de influencia orteguiana. Hemos tratado, también, de analizar desde las dos principales fuentes bibliográficas garcibacquianas de este período -Nueve Grandes filosofos e Introducción al filosofar-, aquellos aspectos, argumentos, principios e ideas de origen orteguiano que, desde la interpretación siempre heterodoxa garcibacquiana, contribuyeron a la gestación y nacimiento de su propio sistema ontológico. Entre los diversos temas que constituyen el propio surgir de la propuesta metafísica garcibacquiana, hemos analizado la confrontación que existe entre dos tipos de racionalidades. Nos referimos a la razón pura y a la razón vital e historicista. Desde esta comparación y confrontación tratamos de analizar y concluir cómo García Bacca se declina inicialmente por la razón vital e historicista y como 
asume, desde el propio seno de la propuesta raciovitalista orteguiana, las reglas de una suerte de dialéctica vitalista.

Hemos analizado, también, qué papel juegan conceptos clásicos de la propuesta orteguiana como el de circunstancia, vida, historia, etc. Hemos tratado de analizar hasta qué punto García Bacca recupera el guante lanzado por el propio Ortega respecto a la discusión metafísica entorno al ser, y la capacidad de ensimismamiento a propósito de su circunstancia de arrojado en el mundo de los hombres. También hemos analizado cómo García Bacca se inspira en algunas de las ideas orteguianas respecto a los diferentes estados ontológicos del hombre en sociedad para, a partir de ahí, generar un nuevo listado de estados que, en el caso de García Bacca, deben concluir en una suerte de estado absoluto que definiría la hombre social como persona.

Hemos analizado el que, a juicio de García Bacca, constituye el fundamento que sustenta la propia actividad filosófica, a saber, el Amor entendido como Eros. A partir de esta identificación del hombre filósofo como hombre enamorado hemos tratado de identificar aquellas características esenciales que definirían -al menos durante este periodo-, la personalidad esencial del filósofo para García Bacca. Entre dichas características hemos analizado conceptos como el de desvergonzado y, especialmente, el concepto de verdad y su relación no sólo con la tradición orteguiana sino, también, con el propio concepto de "perspectiva".

En cualquier caso, el presente trabajo presenta las dificultades clásicas de analizar la vida, obra e influencias de García Bacca desde un punto de vista académico y, más aún, desde el propio espacio limitado de un artículo de investigación. En general, hemos tratado por todos los medios de agrupar, sintetizar y aunar un conjunto de argumentos dispersos y entreverados en el conjunto de la producción filosófica garciabacquiana durante un periodo de tiempo muy concreto, con la única intención de generar una suerte de cartografía general y rigurosa sobre los que, a nuestro modo de entender, constituyen los principales elementos y claves para comprender la verdadera influencia orteguiana sobre la vida y la obra de un filósofo tan poco conocido por el conjunto de la academia filosófica española. 
xagimon@hotmail.com

\section{BIBLIOGRAFÍA}

ABelLÁn, J. L. (1966): Ortega y Gasset en la filosofía española, Madrid: Técnos.

BEORLEGUI, C. (1986): La filosofía del hombre en J.D. García Bacca Vol. I. Bilbao. (1986), La filosofía del hombre en J.D. García Bacca, Bilbao: Universidad de Deusto.

Bergson, H. (1907): L'evolution créatice, París PUF. [Edición en español, La evolución creadora, Madrid: Espasa-Calpe, 1985].

BotTteró, J. (2004): Mesopotamia la escritura, la raqón y los dioses. Madrid: Cátedra.

GARCÍA BACCA. J. D. (1939): Introducción al filosofar, Universidad Nacional de Tucuman (Facultad de filosofía y letras),

(1947): Nueve grandes filósofos contemporáneos. Caracas: Imprenta Nacional, Ministerio de Educación de Venezuela. Nueva edición en Editorial Anthropos, Barcelona, (1990). (1955): La filosofía de Ortega y Gasset. Revista Nacional de cultura. (1956): El estilo filosófico de J. Ortega y Gasset. Revista Nacional de cultura no 114. (1963): Metafísica natural estabilizada y problemática metafísica espontánea. Fondo de Cultura Económica, México.

(2000): Confesiones. Autobiografía intima y exterior, Barcelona: Anthropos.

GIMENO, X. (2014): “El ataque de Juan David García Bacca a la categoría de Sorge heideggeriana”, Estudios Fenomenológicos, no 11, pp. 111-128.

(2015): La categoría del Nos en Juan David García Bacca y la herencia de Antonio Machado, Estudios Filosóficos, no 185.

IZUZQuizA, I. (1984): El proyecto filosófico de Juan David García Bacca, Barcelona: Anthropos.

KANT, I., (2006): Crítica de la Razón pura, Buenos Aires: Losada.

KiRK, G.S., RAVEN, J. E. Y SCHOLFIELD, M. (2006): Los filósofos presocráticos, Ed. Gredos.

MARÍAS, J. (1960): J. Ortega, I. Circunstancia y vocación. Revista de Occidente. Madrid.

ORTEGA Y GASSET, J. (1943), Obras completas de J. O. Gasset. $3^{\circ}$. Madrid: Espasa-Calpe. (1943a): Ensimismamiento y alteración. (1943b): El tema de nuestro tiempo.

(1968): Unas lecciones de Metafísica. Madrid: Alianza.

(2004): Meditaciones del Quijote. Obras completas, Vol. I., Madrid: Taurus/Fundación José Ortega y Gasset.

(2005): El tema de nuestro tiempo, Madrid: Austral.

(2010): ¿Qué es filosofía?, Obras completas, tomo X (1949-1955) obra póstuma.

Madrid: Taurus.

Análisis. Revista de Investigación filosófica, Vol. 2, n. ${ }^{\circ} 1$ (2015): 63-107 
Platón, (2003): Diálogos. Obra completa en 9 volímenes. Volumen II: Gorgias. Menéxeno. Eutidemo. Menón. Crátilo. Madrid: Editorial Gredos. 